\title{
From utilities to mental models: A critical survey on decision rules and cognition in consumer choice
}

\author{
M. Giovanna Devetag \\ S. Anna School of Advanced Studies
}

Pisa, Italy

I thank Vittorio Girotto, Paolo Legrenzi, Eldar Shafir, Massimo Warglien, the editors and three anonymous referees for helpful comments and suggestions on earlier versions of this work. 


\section{Introduction}

In this work we shall critically discuss a selected body of (mainly experimental) studies on consumer behavior, in the light of two general questions. First, can one identify within the vast literature from psychology, marketing, etc., a few stylized facts which might be the grounds of a behavioral theory of consumption parsimonious enough to be useful to economic theorizing, and, at the same time, not in open violation of the evidence on how consumers actually behave? Second, to what extent should such theories be nested into an explicit account of the cognitive processes leading to particular consumption acts?

The tension between normative and descriptive theories of decision making has been a constant object of debate in the social sciences.

While the former have been developed through formal analysis and describe the decisions of hypothetical, fully rational individuals, the latter have derived mainly from psychological research and are aimed at pointing out the behavioral patterns and cognitive mechanisms that constitute actual decisions by real individuals.

Notwithstanding the clear theoretical distinction between the two, the widespread practice in the economics discipline has been to make an extensive use of the normative theory for descriptive purposes as well (see, e.g., Tversky and Kahneman, (1986), and Thaler, (1987), for discussions).

However, by now an immense body of evidence demonstrates that several axioms of the normative theories are empirically falsified. The fact that such deviations are largely systematic and have their origin not in random errors - which would cancel out in the aggregate - but in well identified psychological mechanisms has then posed the problem at least to some economists of how to modify standard theories of decision making in a way that can prove both more realistic and (possibly) formally tractable.

Along these lines, an area of investigation entails precisely turning to psychology with the explicit purpose of trying to identify a set of regularities about human cognition, which may constitute the building blocks for better descriptive models of consumption, saving, investment, strategic interaction, etc.

Several "stylized facts" (some of which will be discussed in the following) about deviations from normative standards have been solidly assessed: for example, roughly summarizing only the most relevant ones, individuals do not exhibit a choice pattern consistent with utility theory; they are not 
sensitive to absolute levels of outcomes but to changes in outcomes relative to a reference point; they evaluate gains and losses asymmetrically; they significantly depart from pure self-interest; they show time-inconsistent preferences and they do not update probabilities according to Bayes's rule, relying instead on intuitive heuristics such as "representativeness" and the like.

Evidence on such facts is by now so ample and robust to seriously question the descriptive validity of most canonic economic theorizing, largely based on the familiar hypotheses of perfect rationality, self-interest, Bayesian updating, and so forth.

Given all that, however, the fundamental theoretical issue concerns what to do about it. And the answers widely vary. At one extreme, the "business-as-usual" approach has still a lot of appeal in the economists profession: that is, neglect the micro evidence and treat the standard axiomatics of consumer choice as an unrefutable generator of restrictions on some purported utility maximizing behavior to be econometrically tested on cross-sectional or time-series data, irrespectively of their behavioral and cognitive plausibility. This is not the place to discuss the epistemological soundness of such an approach dating back at least to Milton Friedman (1953). Here, suffice to telegraphically recall that, first, data which appear to conform to canonic decision-theoretic rationalizations might indeed be the outcome of quite different data-generating processes (see, e.g. Aversi et al, (1999), this volume). Second, notwithstanding the weak discriminatory power of such restriction-testing exercises, a surprisingly large set of falsifying evidence is appearing concerning, primarily but not exclusively, intertemporal choice and risk evaluation (cf. Thaler, (1994), and Browning and Lusardi, (1996)).

The thrust of this work is, needless to say, that any descriptive theory has got to take the behavioral and psychological evidence seriously. But the challenge is certainly hard.

As Richard Thaler puts it,

"The primary lesson here is admittedly a depressing one for economic theorists. The lesson is that their job is much harder than we may have previously thought. Writing down a model of rational behavior and turning the crank may not be enough, and writing down a good model of less than fully rational behavior is difficult for two reasons. First, it is not generally possible to build good descriptive models without collecting data, and many theorists claim to have a strong allergic reaction to data. Second, rational models tend to be simple and elegant with precise predictions, while behavioral models tend to be complicated, and messy, with much vaguer predictions. But, look at it this way. Would you rather be elegant and precisely wrong, or messy and vaguely right?" (Thaler, (1994), p. 198). 
One of the purposes of this work is indeed an assessment of different attempts of being at least "vaguely right" on the grounds of the available evidence.

In section (ii) we shall provide a preliminary overview of the tangled relationships between the psychology of choice and economic modeling. Section (iii) discusses some of the evidence on systematic departures of actual consumption behaviors from the prescriptions of normative theories. Section (iv) introduces some interpretative frameworks aimed at explaining that evidence. A crucial dimension on which alternative descriptive models differ is the importance attributed to explicit cognitive mechanisms as determinants of consumption acts. They will be discussed in section (v). Section (vi) includes some concluding remarks and suggestions for new research directions. Finally, section (vii) includes a brief list of the stylized facts discussed in the text with a guide to references. Few warnings are appropriate. The discussion which follows has no ambition to thoroughly review the immense empirical literature on consumption behavior ${ }^{1}$, and even less so the relationship between psychology and economics (on the latter, cf. the excellent surveys by Camerer, (1995), and Rabin, (1998)).

In particular, we neglect all factors related to the social shaping of preferences, limiting our review solely to the cognitive aspects of the individual consumer seen as a decision maker, and, even within these limits we are forced to leave out important topics such as learning and memory. A critical survey of consumer choice processes with several overlappings with the present one is Bettman, Luce and Payne (forthcoming) ${ }^{2}$. There the evidence is discussed from the point of view of a constructive theory of consumption. While holding lot of sympathy for that approach ourselves, we take a theoretically more agnostic stance, and start from the sheer identification of regularities and "stylized facts" in consumption entailing departures from the normative ("rational") choice models. Only in the second part of this work we shall discuss different theories which try to accomodate such an evidence, with an eye also for the possibility of deriving sorts of "reduced forms" which might be useful as alternative microfoundations of consumption in economic theorizing (cfr. also the companion paper Aversi et al., (1999), in this volume). Another survey that explores recent contributions on decision making on the basis of alternative views on rationality is Mellers et al., (1998). There one can find a discussion of the evidence interpreted from the two perspectives of "preference-based decisions" and "rule-following". While the survey does not

\footnotetext{
${ }^{1}$ The reader interested in a more extensive review of recent empirical literature on consumer behavior should refer to Jacoby et al., (1998).

${ }^{2}$ See also the preceding review in Payne et al., (1992)
} 
include studies on knowledge representation, which is the topic discussed in section (v), it does contain references on judgment, risk attitudes and emotion-based choice, which are left out of the present work.

A final warning is necessary: our description of both experimental evidence and theories is necessarily concise and therefore largely incomplete, as we aim at highlighting the general points which emerge from the issues discussed, but we are forced to do so at the expense of exaustiveness and detailed formalization. The reader should therefore refer to the works cited for more extensive expositions.

\section{The Psychology and Economics of Consumer Behavior: A Preliminary Overview}

The relationship between economics and psychology, especially regarding consumer behavior, has a long history, with economic theory switching back and forth from a psychological foundation of its models. The issue is closely related to the behavioral validity and descriptive power of economic theories of consumption (for a discussion of the historical background, see Lewin, (1996)).

Making a long story very short, the controversy goes back at least to the debates over the notion of utility, originally entrenched with strong psychological connotations, primarily identified, following Bentham, with utterances of pleasure and pain.

However, most of the subsequent history may be read as an effort to render economics increasingly "psychology-free", and therefore increasingly based on purely deductive foundations. In this vein, the notion of "utility" has gradually become a sort of meta-theoretical point of reference - a handy shorthand to express the deductive derivation of behavior from the coherent pursuit of some (unknown) goal by economic agents.

The axiomatization of micro behavior- nowadays familiar also in most textbooks - builds upon the theory of revealed preferences, which finally permitted to abandon the very notion of utility (still carrying its somewhat ambiguous "psychological" meaning) and to rely exclusively upon purported regularities in observed behavior, in light of the principle by which individuals want what they choose and choose what they want - thus "revealing" their preferences ${ }^{3}$ (Lewin, 1996). In so far as

\footnotetext{
${ }^{3}$ Note, however, that well defined preference relations can always be interpreted as the outcome of the maximization of an underlying utility function. See Samuelson, (1938), and Varian, (1982).
} 
the goals - whatever they are - are coherently pursued, one should find the observational equivalence between descriptive and normative theories of decision making.

But here come the problems stemming from the experimental evidence which has provided rigorous tests of the foundations of the theory, proving indeed that most of the basic properties of preference relations and the underlying utility theory are systematically violated by empirical subjects.

So, for example, the consumer of economic theory is based on a perfectly rational decision maker whose well defined and stable preferences over a particular good do not depend on anything other than the good in question. That is, neither the presence or absence of other goods in the market nor the particular elicitation method have any influence on her preference relations. The decision maker knows the entire set of alternatives available, assigns a defined utility value to each one and then chooses by selecting the set of options that maximizes her overall utility.

However, the evidence on various forms of bounded rationality is ubiquitous.

In particular, the bounded nature of human rationality invalidates the rational choice model in more than one respect: In fact, individuals not only lack the knowledge and computational skills needed to solve the complex optimization problems that the theory requires, limiting themselves to applying satisficing "rules-of-thumb" rather than optimizing algorithms. They also often construct their preferences at the moment of choice - rather than simply revealing them - through a complex and partly circular process of interaction among goals, outcomes, framing of the situation, contextual elements, mental representations and the particular decision rule utilized.

Any normative (or rationality-based descriptive) model of consumer choice must include the principle of independence of irrelevant alternatives, which states that any two alternatives maintain the same respective value for the decision maker independently on the set of options to which they belong. Another, related assumption requires that preferences be transitive. Both assumptions have been shown to be implausible at a descriptive level.

Other normative principles are even more compelling and fundamental for normative accounts of rationality.

For example, dominance is so intuitively appealing to appear almost tautological (see Kreps, (1990)); however, experimental studies have shown that individuals do sometimes violate it.

Another assumption which is so fundamental to be often taken for granted is invariance, according to which preferences for a set of alternatives are invariant with respect to the particular elicitation method utilized or to alternative (but formally equivalent) descriptions of the choice problem. 
However, hundreds of experiments on framing effects and preference reversals (cf. below) are there to demonstrate that such an apparently obvious principle does not hold.

Finally, even the axiom of completeness appears exceedingly demanding, given that it excludes the possibility (in reality far from uncommon) that the decision maker may be unable to make comparisons between options.

In an extreme synthesis, the psychological evidence - part of which shall be discussed in the next sections - seriously undermines the validity of the basic principles underlying both preference and choice, therefore posing the question whether economic theories should indeed be axiomatics, or whether on the contrary one should primarily use "positive" psychological accounts in order to extract some inductive generalizations likely to generate the observed behavioral patterns. In between stand theories which do take on board the experimental evidence on various departures from standard axiomatic theories, but still derive predictions on behavior from some general "anthropological" principles. Among them, possibly the most famous is Prospect Theory (Kahneman and Tversky, (1979), cf. below) - which seems to do a better job of describing choice under uncertainty than von Neumann and Morgestern's expected utility theory ${ }^{4}$, reflecting humans' asymmetric attitudes towards risk and their sensitivity to changes rather than states (the latter being the specification in the choice domain of a general principle of psychophysics). In any case, whatever approach is chosen, taking seriously the systematic discrepancies between standard normative theory and empirical evidence implies some return to the psychological roots of the theory itself.

This is the case of the rediscovery - in a modified "Benthamian" fashion - of the psychological notion of utility by Kahneman and Tversky ${ }^{5}$, and it is even more so in the approaches which build on explicit cognitive dynamics as drivers of consumption acts (cf. section (v), below).

But how deep should one go in terms of psychological foundations of consumption theory? Should one be content of that sort of blackboxing of cognitive and emotional mechanisms implicit in any utility-based formalization? Or on the contrary, should one take implicitly on board the mental models shaping consumption patterns? In the light of this devide, in the following sections (iii), (iv) and (v) we shall discuss in sequence:

\footnotetext{
${ }^{4}$ In a similar spirit, in another domain, hyperbolic instead of exponential discounting of intertemporal utility seems a good approximation of individuals' impatience and desire for immediate gratification, apparently the main source of time-inconsistent preferences (see, e.g., Loewenstein and Elster, (1992), and references therein).
} 
a) approaches that view consumer choice as part of a utility-driven theory of decision making, and

b) approaches that explore more in-depth and less observable cognitive processes whose link with choice is more indirect and mediated.

To the former belong a good deal of the "biases and heuristics" research which we shall consider in the next section. Conversely, the latter include studies on mental representations and categorization processes, together with some developments of the psychology of reasoning.

Inbetween these two main classes one should place some contributions on reason-based choice and constructive choice processes. The former are attempts to analyze choice from the point of view of the inner motivations that guide the decision maker and which trace some parallels between the study of decision making and the psychology of reasoning. The latter is an attempt of an integrated framework allowing a unified interpretation of most empirical facts about consumer choice that research on biases and heuristics has highlighted.

\section{Biases and Heuristics in Consumer Behavior}

The program of research on judgment under uncertainty introduced by Kahneman and Tversky several years ago came to be known as heuristics and biases approach. The goal of the research was to "understand the cognitive processes that produce both valid and invalid judgments" (Kahneman and Tversky, (1996), p. 582). Along these lines, research on decision making, both by Kahneman and Tversky and by other psychologists has aimed at understanding the mechanisms that produce both valid decisions (from the point of view of the normative theory) and biased ones.

The study of the discrepancies between the two has indeed generated a well documented set of systematic errors or biases that individual make when forming judgments about events or when making decisions. The detection of systematic departures from normative rationality, within the framework of most research on judgment and decision making, is the essential starting point to gain some insight into the cognitive processes underlying both judgments and decisions (see Kahneman and Tversky, (1982), Kahneman and Tversky, (1996), and Shafir, (1993b) for discussions).

Let us start with violations of some of the axioms of normative models, which are attributed to the effect of context, to the use of particular decision heuristics or otherwise to a specific tendency on

\footnotetext{
${ }^{5}$ Indeed, in some weaker sense, this is also the case of Lancaster's idea of preferences defined over hedonic attributes of goods (Lancaster, (1971)).
} 
the part of individuals to encode and evaluate outcomes in a manner inconsistent with standard notions of rationality.

Biases and context-dependent preferences

The idea that our choices depend on the context, although possibly obvious to common sense, is at odds with the normative models of choice, according to which preferences are exogenous constructs whose ordering cannot be altered by modifying contextual parameters.

Restated differently, borrowing the well know definition in March (1994), the theory of rational choice in its purest form obeys the "logic of consequence", by which individuals attach consequences to alternative courses of action on the basis of underlying preferences which are assumed to be known, precisely defined, internally coherent and stable ${ }^{6}$. This is the logic by and large prevailing in microeconomic models. On the other hand, behavioral research on decision making stresses the fact that an individual's preferences are actually often the result of a (more or less explicit) constructive process, through which decision makers try to assess "what they prefer" by anchoring their estimation to their perceived identity, their goal hierarchy, but also to their "framing" of the situation and various clues offered by the environment. Again, following March (1994), we may say that real life decisions often obey the "logic of appropriateness" ("what is appropriate to do for somebody with my identity in a situation like the one I am facing?"). In this perspective, the importance of context - broadly defined as to include aspects that go from the composition of the decision maker's feasible set, to the amount and type of information available as well as to social influences of various sorts - is crucial in shaping preferences and decision acts.

Given this inclusive definition of what context means in relation to decision making, note that the experimental findings on consumer choice that will be discussed below are based on a much more restrictive notion of context, essentially referring to the composition of the consumer's choice set and the role it plays in determining decisions that violate one or more axioms of standard rational models (indeed "context effects") ${ }^{7}$. In choice situations, and particularly in consumer choice, in fact,

\footnotetext{
${ }^{6}$ Although possibly not stable over time, but certainly stable across contexts.

${ }^{7}$ We leave out any methodological remarks about the use of experiments in psychology and economics, and related disagreements between the two disciplines about the "correct" methodology. While the issue is certainly an important one, it would lead beyond the limits of the paper. However, see Camerer, (1995), for a thorough review of experimental research on decision making - both by psychologists and economists - rich of critical methodological digressions.
} 
context effects can be defined as changes in the choice process or in its results as a function of the particular composition of the choice set (Ratneshwar et al.,(1987)).

For example, one usually judges the convenience of a particular brand in the context of all other brands available. If the composition of the other brands is modified (some new brands are added and/or others are eliminated), the person may as well modify her evaluation of the brand in question. Experiments demonstrate that even such "bland" contextual manipulations produce choice behavior that poses serious problems to the validity of rational decision making theories. It is plausible to imagine that such effects are likely to be magnified (rather than cancelled) by additional contextual variables that these types of studies exclude from analysis.

\section{Context effects}

A basic principle of economics states that inefficient, dominated alternatives should not affect choice.

In consumer theory the principle is specified by saying that the introduction of dominated products in the consumer's choice menu should not alter the preference ordering between existing products (and should not alter their "market share" at all).

A further specification of this assumption is the so-called regularity condition, which derives from the principle of independence from irrelevant alternatives. Formally, for any alternative $\mathrm{x}$ belonging to the set $\mathrm{A}$, where $\mathrm{A}$ is in turn a subset of $\mathrm{B}$, the regularity condition states that the probability of choosing x out of A cannot be smaller than the probability of choosing $\mathrm{x}$ out of $\mathrm{B}$.

$\forall \mathrm{x} \in \mathrm{A} \subseteq \mathrm{B}, \operatorname{Pr}(\mathrm{x} ; \mathrm{A}) \geq \operatorname{Pr}(\mathrm{x} ; \mathrm{B})$

In other terms, under the regularity condition, the overall attractiveness of a particular option of a choice menu cannot be increased by increasing the number of other options available.

At a more aggregate level, the introduction of a new product competing with pre-existing products should not produce an increase in the market share of one or more of the pre-existing products.

Despite the intuitive appeal of the regularity condition, a number of experiments have shown that consumer violate it in a variety of settings. In particular, the violation most strongly occurs when the option being added is dominated by one of the pre-existing alternatives. 
For example, imagine that a group of subjects has to choose between two products A and B. A has superior quality but it's more expensive than B. Subjects thus face a price/quality tradeoff. Fig. 1 represents $\mathrm{A}$ and $\mathrm{B}$ in a two-dimensional diagram in which a quality index is reported on the $\mathrm{Y}$ axis and convenience (as it may be expressed by $1 / \mathrm{P}$, where $\mathrm{P}$ is the price) is reported on the $\mathrm{X}$ axis.

Imagine that $55 \%$ of subjects actually choose A, while the remaining $45 \%$ choose B.

Now, suppose a third product C (usually named decoy) is added which is asymmetrically dominated by $\mathrm{B}(\mathrm{C}$ is inferior to $\mathrm{B}$ both in price and quality, but it still presents a tradeoff with $\mathrm{A}$ ).

$\mathrm{C}$, in other words must fall within the shaded area in fig. 1 to be dominated by B only.

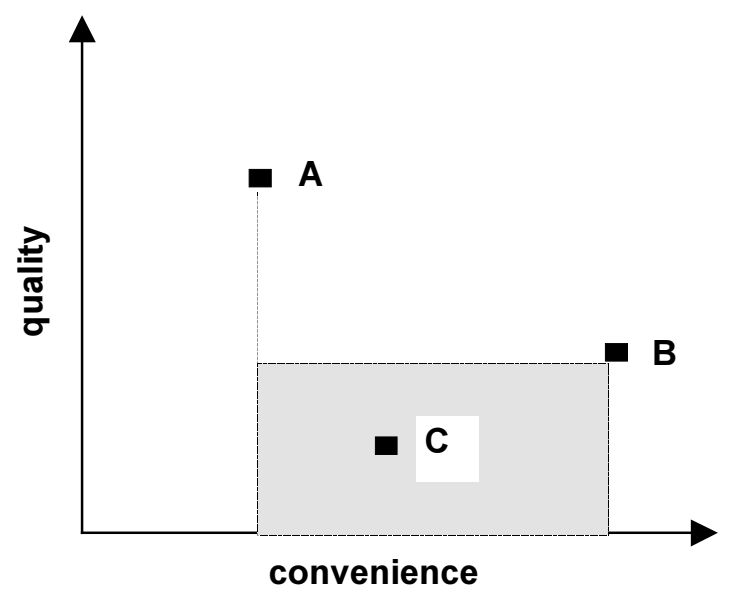

fig. 1

Various experiments (Huber et al., (1982)) have shown that in this second case no one chooses C, which is clearly inferior, but its mere presence causes a substantial shift of preferences from A towards B (in our example, $60 \%$ of subjects would choose B and $40 \%$ would choose A).

The attraction effect is one of the most robust biases in consumer choice. Experiments have been replicated using different product classes, from chocolate bars to TV sets to beer. The pattern is typically invariant: The average gain of the target option ( $\mathrm{B}$ in our example) in terms of preference shares when the decoy is added revolves around $9 \%$.

Various explanations have been advanced, some of which postulate the influence of perceptual mechanisms (Heath and Chatterjee, (1991)), others (Tversky and Simonson, (1993)) the use of particular decision heuristics based on pairwise comparisons among alternatives (which would favor B), or the consideration that B is the option whose choice is most easily justifiable because of its relative superiority (Simonson, (1989)). 
Finally, other experiments relate the emergence of the phenomenon to both perceptual and categorization effects (Pan and Lehmann, (1993)).

Factors that were found to reduce the relevance of the attraction effect are, among others, a high degree of familiarity with the product category, a high level of involvement in the particular choice (which is supposed to activate more accurate decision processes), and brand-loyalty phenomena (see Mishra et al., (1993); Kardes et al., (1989); Ratneshwar et al., (1987); Stewart, (1989)).

(For further developments of the attraction effect see also Aaker, (1991); Heath and Chatterjee, (1991); Heath and Chatterjee, (1995)).

Dhar and Simonson (1992) have found out that the probability of an option being chosen can be enhanced simply by making it the "focal option" of a comparison.

For example, in one of the experiments they ran, subjects were asked to imagine having to consider the choice of an MBA program, and having applied to both Harvard Business School and Stanford Business School. Subsequently, half the subjects were asked to rate, on a numerical scale, how more or less attractive the Harvard option appeared to them compared to the Stanford option, and how strongly they preferred being enrolled in an MBA program in Harvard compared to Stanford (Harvard was thus rendered "focal" with respect to Stanford). The other half of the pool was given the same questions, except that Stanford instead of Harvard was the focal option. Both groups were finally asked to imagine being offered admission to both schools and to indicate which one they preferred. Results show that both Harvard and Stanford were chosen $20 \%$ more often on average when they were the "focal options" compared to when the competing alternative was the focal option. The experiments were replicated with different types of choices; the effect was greater when subjects had to recall the relevant characteristics of alternatives from memory, compared to the cases in which all the relevant information about the options was provided by the experimenter.

Two explanations can account for this effect according to the authors. The first one refers to the contrast model of similarity developed by Tversky (1977), whose basic properties have been recently extended from the domain of similarity judgments to the domain of preference (Houston et al., 1989). While most models used in psychology and marketing rely on a geometric definition of similarity as relative distance between objects in the ideal space defined by attributes, the contrast model is based on the assumption that judgments of similarity between two items are the result of a 
linear combination (or contrast) of the measures of their common and distinctive features (Tversky, (1977); Tversky and Gati, (1978)).

One of the relevant properties of the model is its capacity to explain apparent anomalies in judgments of similarity, among which is the fact that similarity judgments are often not symmetrical, but rather depend on the direction of the comparison. In everyday judgments, we often tend to make directional statements of similarity, tending to select the more salient item as the referent of the comparison (for example, we say "the daughter resembles the mother, rather than "the mother resembles the daughter"). More formally, the contrast model predicts that the following two statements (Tversky and Gati, (1978)):

1. Assess the degree to which $a$ and $b$ are similar to each other.

2. Assess the degree to which $a$ is similar to $b$.

should yield two different answers (such prediction is in accordance with experimental results). While the first form does not make any of the two items appear more salient than the other, the second form will focus the judge's attention to the subject of the comparison, $a$, more than to the referent $b$. As a result, the subject's distinctive features will be more salient than the referent's distinctive features, causing asymmetries in evaluation ${ }^{8}$.By extending the "direction of comparison" effect from the domain of similarity relations to the domain of preference and choice, when the distinctive features of an option are perceived to be positive, the option may be preferred more often when it is the subject (or focus) of the comparison that when it is the referent (Houston et al., (1989)).

Another explanation involves the principle of loss aversion (cf. below),(Tversky and Kahneman, (1991)), according to which losses loom larger than gains in choice. Both gains and losses are computed with respect to a reference point (generally represented by the individuals' status quo). In this case, losses and gains will be valued taking the focal option as the reference point, thus making losses that come from rejecting the focal option loom larger than corresponding gains.

As a result, the focal option will be favored (see also Johar and Creyer, (1993); Dhar and Sherman, (1996)).

\footnotetext{
${ }^{8}$ Note that geometric models do not account for asymmetry. Incidentally, note that similarity judgments have been likewise shown to violate transitivity (Tversky and Gati, (1978)). The results can again be explained by the Contrast Model.
} 
Simonson and Tversky (1992) propose the notion of tradeoff contrast as a possible generalization for a variety of context effects, among which the attraction effect can be considered a particular case.

The principle of tradeoff contrast can be intuitively grasped if one imagines it analog to a sort of "perceptual illusion": In everyday settings, we often tend to perceive entities in the relation to the "background" against which they appear to us. Thus, the same figure will be perceived differently according to the "ground" against which it is positioned.

In much the same way, a product may be judged as more desirable if placed among "inferior" products, and vice-versa.

This judgmental bias can also influence the way in which people value tradeoffs between attributes. As an example, suppose you want to buy a new computer and you are offered the following two options (Simonson and Tversky, (1992)):

-computer $\mathrm{X}$, priced at $\$ 1,200$, with $960 \mathrm{~K}$ memory

-computer Y, priced at $\$ 1,000$, with $640 \mathrm{~K}$ memory.

Let this be the target pair of options. $\mathrm{X}$ is the high price, large memory option, while $\mathrm{Y}$ is the less price, smaller memory option.

You have to resolve a tradeoff, as your choice depends on your willingness to pay $\$ 200$ more to get $320 \mathrm{~K}$ of additional memory: restated differently, the "cost" for you of obtaining $1 \mathrm{~K}$ additional memory is $\$ 0.625(\$ 200 / 320 K)$.

Simonson et al. found out that people are more inclined to choose the more expensive computer if the choice menu includes other pairs of options for which the price/quality exchange rate is higher than $\$ 0.625$, that is pairs of options for which the "cost" of additional memory is higher than the one implied by the target.

Similarly, if the choice menu includes pairs of options for which the cost of additional memory is lower than the target, people are more inclined to select the less expensive computer in the target. Tradeoff contrast was found to emerge in two different ways: The first one (background contrast) refers to alternatives encountered by consumers during past purchase experiences. The second (local contrast) refers to pairs of options that are included in the same choice set along with the target. 
Another principle related to the emergence of context-dependence phenomena is extremeness aversion, which may account for the compromise effect which was found to emerge in experiments. In many settings, individuals seem to avoid options which present extreme values, preferring instead options that represent a compromise between two extremes.

This particular anomaly may be justified by the notion of loss aversion, which can be naturally extended to contexts of consumption acts by picturing the attributes of each good as advantages and disadvantages relative to all other goods in the choice set (note that in this case the reference point against which gains and losses are valued is not the status quo, but each of the two options in turn). By extending the notion of loss aversion to a context of choice between alternatives, it is possible to hypothesize that individuals tend to weigh disadvantages more heavily than corresponding advantages when evaluating different options.

Consider the three options represented in fig. 2:

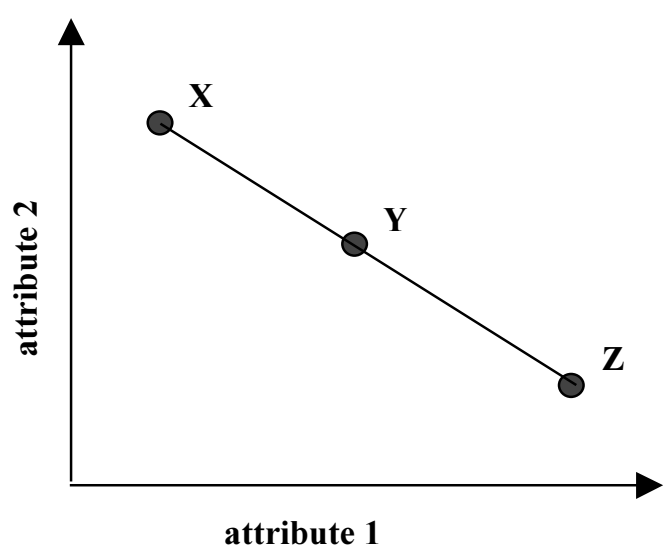

fig. 2

Option $\mathrm{Y}$ has middle values with respect to $\mathrm{X}$ and $\mathrm{Z}$ along both dimensions.

In fact, $\mathrm{X} 1<\mathrm{Y} 1<\mathrm{Z} 1$, and $\mathrm{X} 2>\mathrm{Y} 2>\mathrm{Z} 2$.

The two "extreme" options $\mathrm{X}$ and $\mathrm{Z}$ present large advantages and disadvantages relative to one another, and smaller advantages and disadvantages relative to $\mathrm{Y}$.

$\mathrm{Y}$, on the other hand, presents small advantages and disadvantages relative to both.

Under the hypothesis of loss aversion, individuals select the option that minimizes the overall disadvantages (losses), and this leads to the choice of Y. 
Therefore, $\mathrm{Y}$ will benefit from the presence of both $\mathrm{X}$ and $\mathrm{Z}$ in the choice menu relative to binary choices between $\mathrm{Y}$ and $\mathrm{Z}$, or $\mathrm{Y}$ and $\mathrm{X}$ alone.

From a decision-theoretic point of view, this result is another violation of the regularity condition, although no dominated option is added, since the middle option is supposed to "score" better when a third option is introduced.

Simonson and Tversky introduce the two terms of compromise and polarization to distinguish between the case in which extremeness aversion applies to both attributes from the one in which it applies to one attribute only.

That is, a compromise effect occurs when adding $\mathrm{Z}$ to the $(\mathrm{X}, \mathrm{Y})$ pair favors $\mathrm{Y}$ over $\mathrm{X}$ and adding $\mathrm{X}$ to the $(\mathrm{Y}, \mathrm{Z})$ pair favors Y over Z (see also Wernerfelt, (1995)).

In the case of polarization, only one of the two outcomes occurs.

The experimental evidence above described (see also Simonson, (1993) for a review) suggest the fact that the process of evaluation of alternatives is comparative in nature, that is the attractiveness of every option closely depends, among other factors, on the options with which it is compared.

Tversky and Simonson (1993) propose a model of context-dependence choice which expresses the choice function as a linear combination of three components: the context-independent value of an option, the effect of the background, that is of choice sets encountered in the past, and the impact of the current choice set. Each component is weighted according to its relative importance in determining the overall attractiveness of an option. For values of weights $=0$, the model reduces to the standard model based on utility maximization. The authors' model can contribute to make sense of empirical evidence on violations of normative principles, in particular it incorporates the two phenomena of tradeoff contrast and extremeness aversion above described.

Shafir et al. (1990a) have developed a similar model - called the Advantage Model - which takes the "comparative" nature of choice into account helping make sense of certain experimental phenomena like the ones described.

According to their model, the overall value attached to every option in a choice set derives from the use of both absolute and comparative strategies of evaluation, the results of which are subsequently combined. While the model has been originally formulated for choice involving monetary outcomes, its results can be easily extended to nonmonetary choices as well. 
Framing

Framing effects are maybe the most radical challenge to normative models of choice, in that they violate the axiom of description invariance ${ }^{9}$, which is normally considered so essential to be not even explicitly mentioned among the principles of rational choice theory. In effect, framing can be considered an extreme example of context-dependence, where preference reversal occurs by simply modifying the description of (otherwise identical) sets of alternatives.

In what is probably their most famous experiment, Tversky and Kahneman (1981) proposed to two different groups of subjects a choice between two alternative programs to combat an unusual Asian disease expected to kill 600 people in the U.S. In one version of the problem, the two programs were described in terms of the estimated number of lives that each program could be expected to save, while in another version the same two programs were described in terms of the number of lives that would be lost in each case. Although the two descriptions were formally equivalent, the shift of preference was dramatic: in the "lives saved" version, $72 \%$ of subjects preferred the less risky program, allowing to save 200 people for sure; in the "lives lost" version, $78 \%$ preferred the more risky program, accepting one-third of probability of letting 600 people die.

Analogous framing effects were found in the domain of riskless choice. So, for example (Levin and Gaeth, (1988)), consumers seem to be more willing to buy a product when this is described as being "75\% lean" than when it is described as having "25\% fat". The rationale for the existence of framing effects again has to do with the fact that individuals are more sensitive to losses than to equal-sized gains, where gains and losses are calculated with respect to a reference point (a relevant implication for choice under uncertainty is the emergence of risk aversion in the domain of gains, and riskseeking behavior in the domain of losses).

So, for example, in the experiment above, individuals perceive alternatives in the "lives saved" version as gains with respect to a reference point represented by the death of 600 people if nothing is done. On the contrary, in the "lives lost" version, the two programs are encoded in terms of the losses they yield with respect to a reference point represented by the current situation in which nobody has yet died.

\footnotetext{
${ }^{9}$ On violation of another fundamental axiom, procedure invariance, see, e.g., Slovic and Lichtenstein, (1969), Tversky and Thaler, (1990).
} 
Reference-dependence certainly appears to many as a plausible psychological characteristic of human judgment and perception, which, as far as the choice domain is concerned, could be in itself accounted for by some "mild" modification of standard utility theory (A reference-dependence model of riskless choice based on experimental evidence has been developed by Tversky and Kahneman, (1991); see also Rabin, (1998), for a discussion). However, what experiments on framing show is that the reference point can be very easily manipulated, with dramatic effects on preference and choice. Moreover, individuals may set up their own reference point based on (alternatively) their status quo, their aspiration levels, possibly somebody else's current status, or some weighted combination of these. In addition, the use of any one of such reference levels may evolve over time due to adaptation (see Tversky and Kahneman, (1991)). Such facts are particularly disturbing for advocates of standard theory and likewise challenging for any behavioral theory of consumption, because once reference-dependence is included in the utility function, the specification of what reference point will be used in a particular choice situation is both difficult to assess and essential to allow predictions on behavior.

\section{Heuristics}

Let us now consider the main decision rules that have been identified in studies on consumer behavior. A heuristic is commonly defined as a rule or strategy of behavior to be used in solving problems. Heuristics have different levels of complexity and accuracy depending on such factors as the amount of information available, the level of individuals' rationality and the level of involvement in the particular task at hand (Hogarth, (1987)).

The main lesson from studies on heuristics is that consumer decision making strategies are contingent on multiple variables including the complexity of the task, the amount of information processed, the existence of time constraints, the nature of contextual components.

Several experimental studies have been conducted which aim at classifying different strategies through measures like their degree of accuracy, the effort level they require, the amount of information processed and how different pieces of information are put in relation to one another (see, e.g., Payne, (1976), for a classic study; Bettman et al., (1991), Payne et al., (1992)). The "normative" yardstick in this case is provided by decision rules which resemble the rational model, 
inasmuch as they use all the information available in a manner consistent with rationality and prove relatively "immune" from context influences or preference elicitation methods.

With respect to contributions on biases, literature on heuristics shifts the focus of attention from the outcomes of choice and their consistency with normative standards, to the underlying cognitive mechanisms producing those outcomes. In this respect, studies on heuristics represent an important step towards a more constructive view of consumer decision making, in that they open the "black box" of the decision maker's inferential machinery and its relations (often ambiguous and contingent on the particular nature of the task) with preference formation and choice.

The two areas are closely related, as the use of certain decision making procedures is tightly associated with violations of rational choice models. However, the shift of focus from outcomes to processes themselves implies the adoption of a partly different theoretical framework. If research on biases demonstrates that the paradigm of full rationality must be relaxed in order to account for some well-documented "distortions", the framework underlying choice processes starts from the Simonian paradigm of bounded rationality and goes further in trying to identify its procedural manifestations, instead of simply invoking it as a general justifying principle for deviations from normative standards ${ }^{10}$.

Bettman, Johnson, and Payne (1991) trace a classification of the most common heuristics together with an indication of the situations in which each of them is most likely to occur. The following brief description is largely based on their work.

The Weighted Additive (WADD) Rule can be considered the heuristic that consumers are supposed to use according to normative theory of decision making.

It implies taking into account the values of each alternative on all the relevant attributes and considering the relative importance of each attribute to the decision maker.

According to the WADD rule, a weighted value for each attribute is obtained by multiplying the weight times the attribute value. All attribute values are then summed up to arrive at an overall evaluation of the alternative. The alternative that presents the highest overall evaluation is then chosen.

\footnotetext{
${ }^{10}$ This statement requires some explanation: the critique to the general lack on interest in the explicitation of the cognitive mechanisms underlying decision making is obviously not addressed to psychologists, who - by definition! - have always been mainly concerned with such topics; rather, it refers to other social scientists, and in particular to economists.
} 
In the real world, this particular heuristic is seldom used, due to the large amount of information processing that requires. Moreover, even though consumers are normally aware of the relative importance of each attribute to them, nevertheless they are not always able to assign weights.

As a result, simpler heuristics are usually preferred. A simplification of the WADD rule eliminates different weights for the attributes assuming that they all are equally important. An option is selected by simply summing the values of the attributes for each alternative and then comparing the results.

The Satisficing Heuristic requires a cutoff level to be set for each attribute. Alternatives are then evaluated one at a time in the order in which they occur, and the value of each attribute is compared to the cutoff level. If the value of any of the attributes is below the cutoff level, that alternative is rejected. The first alternative that meets the cutoff requirements for each attribute is then chosen. If no alternatives pass the cutoff requirements, then the cutoff levels are relaxed and the process repeated all over again.

The alternative that will be selected depends on the level of the cutoffs and on the order in which alternatives are considered. For instance, if option A and option B both meet all the cutoff requirements, then the choice of either one will depend on which one is evaluated first.

The Lexicographic Heuristic requires a complete ranking of the attributes in terms of relative importance. The consumer determines the most important attribute and then examines the values of all alternatives on that attribute. The alternative that presents the best value on the most important attribute is selected. If two alternatives are equal in the sense that they present equal values on that attribute, then the second most important attribute is considered, and the procedure continues until one option is chosen.

A widely known heuristic is the Elimination-by-Aspects (EBA). The first formulation of this model of choice is due to Tversky (1972). It is based on the idea that individuals do not choose objects per se; rather, they tend to choose the collection of features (or aspects) of which these are composed. In its original formulation, EBA determines that at every step a particular aspect is picked randomly. Then, all alternatives that do not have that aspect are eliminated; if only one option is left, the process is over; otherwise, a second aspect is selected and other alternatives eliminated until there is only one left (see also below).

The Elimination-by-Cutoffs Heuristic is procedurally very similar to the lexicographic rule, with the difference that a cutoff level is established for each attribute and all alternatives that do not meet the 
cutoff requirement are eliminated. At every step an attribute is selected according to its relative importance, and alternatives that do not meet the cutoff level for that attribute are eliminated. The process continues until there is one option left.

The Majority of Confirming Dimensions Heuristic determines that comparisons be made between pairs of alternatives. The values on each attribute are compared between two alternatives. The alternative with a higher number of winning attributes remains, while the other is rejected. The winner is then compared with the next alternative in the set. The process of pairwise comparisons continues until all alternatives have been evaluated and the final winning identified.

It is to be noted that the use of a similar heuristic can in part account for the attraction effect (cf. above). Tversky and Simonson (1993) propose a tournament-like model of choice, in which each option is compared against each other option of the choice menu in terms of its winning attributes. When one of the options is asymmetrically dominated, it is easy to verify that the option that dominates it is bound to be selected.

The Frequency of Good and Bad Features (or "Frequency Knowledge") is a very simple heuristic that implies that consumer develop certain criteria to determine that certain features are good or bad: Then, the consumer may simply count the number of good and bad features. The choice can then vary according to whether the consumer prefers the option with the smallest number of bad features or the one with the biggest number of good features (see also Alba and Marmorstein, (1987)).

Several other types of simpler heuristics seem to be used by consumers in various types of situations: maybe the simplest and the most common one in low involvement situations is the habitual heuristic: "Choose what you chose last time". Another heuristic, called affect referral (Wright and Barbour, (1975)) consists in recalling from memory previously formed global evaluations for familiar alternatives and choose accordingly.

Other heuristics used in low-involvement choices are (Hoyer, (1984)) strategies "price-oriented" (buy the cheapest brand), strategies "performance-oriented" (buy the brand that seems the best), affective strategies (buy the brand that is the most familiar to you), "in-store" strategies (buy the first brand that you find), and strategies that are combinations of the preceding ones.

The most usual distinction is between compensatory and noncompensatory heuristics. 
In general, a heuristic is compensatory if good values on some attributes can compensate for poor values on other attributes. For example, rules such as the WADD or equal weight are defined as compensatory.

On the contrary, a rule is defined as noncompensatory if it does not permit such compensation. Traditionally noncompensatory heuristics are also called sequential, as they typically involve a sequential elimination of options or subsets of options: examples of this second type are the Lexicographic rule, or the Elimination-by-Cutoffs.

Compensatory rules are normally considered more difficult and elaborate, in that they require a greater processing effort. Therefore, especially in cases of low involvement purchases, consumers tend to avoid using them. It is also suggested that the use of compensatory rules implies the evaluation of tradeoffs between values that can sometimes be emotionally difficult (Hogarth, (1987)).

Sequential heuristics, on the other hand, are less efficient than compensatory ones because they allow a greater probability that a sub-optimal alternative is chosen. In fact, with EBA rule, for any set of alternatives, a particular sequence of aspects can be specified that determines the worst option in the set to be selected.

In a large number of concrete examples, consumers may use mixed strategies according to the phase of the choice process. For instance, a typical choice strategy may imply an initial step in which bad alternatives are eliminated using a very simple sequential heuristic (such as EBA, or Eliminationby-Cutoffs). Then, the few options left may be examined more carefully through the use of a compensatory strategy.

Agendas

Kahn et al. (1987) report a TV commercial that says: " Only 10 airline companies offer flights from Los Angeles to London: of these, only 5 offer non-stop flights: of these 5 companies, only 3 use Jumbo 747: of these 3, only 2 have special plans for business class flyers: Finally, of these 2, only one offers a flexible and reliable service: Ours". 
The commercial not only suggests customers which attribute to consider when choosing an airline company, but also in which order to consider them. Kahn et al. report the commercial as an example of agenda (see, e.g., Tversky and Sattath, (1979), Hauser, (1986)).

An agenda can be defined as a sequence of constraints that operates to progressively restrict the set of alternatives. It may be viewed as a generalization of the class of noncompensatory or sequential heuristics.

Agendas can be of two types: top-down or bottom-up. The crucial variable in determining the use of either one has been found to be the consumer's level of familiarity with the product (Wagner and Klein, (1993)). The following is a hypothetical low-familiarity scenario, in which a top-down agenda is used to make a decision:

Imagine finding yourself in New York for the first time in your life and you must choose in which restaurant to eat: The set of alternatives available to you is close to infinite, and you have no recollections of nice restaurants you have heard of, nor can you count on some friend's advice. The only tool you can use is a guide of restaurants. Most likely you may start by categorizing restaurants based on the type of food they offer (Chinese, Italian, French, etc.), then select the category that you like the most. At this point you have already reduced the set of alternatives to a much smaller number. Then, assuming you picked Indian restaurants, the next step might be to spot Indian restaurants that are located near your hotel in Manhattan. This second constraints further restricts the set of your possible choices, and then you may make your final selection based on the price range, or some other features that are relevant to you.

In the following high-familiarity scenario a bottom-up agenda is used instead:

Imagine being in the town where you usually live and you want to go out for dinner. Since you are already familiar with restaurants in your neighborhood, you may start thinking at what restaurant is best in each category (Chinese, Italian, French, etc.) and then you may make pairwise comparisons between the "winners" to arrive at your final selection.

Sometimes constraints are self-imposed, otherwise they can be imposed by the way information about a product is provided (see Kahn et al., (1987)). 
Agendas, like other heuristics belonging to the noncompensatory class, can sometimes lead to inefficient choices, especially in the top-down case. For any alternative, in fact, a particular sequence of constraints can be found that will lead the decision-maker to select it. As a result, dominated options have a positive probability of being chosen.

The following is an example from Hauser (1986) on a hypothetical choice between air travel tickets (tested experimentally in Devetag et al., (1996)):

x. Japan via Japan Air Lines (JAL) with free drinks on the plane:

y. Japan via Northwest Orient (NW):

v. Japan via Japan Air Lines (JAL):

z. Hong-Kong via Northwest Orient (NW).

Option $\mathrm{v}$ is clearly dominated by option $\mathrm{x}$ in the whole set $(\mathrm{x}, \mathrm{y}, \mathrm{v}, \mathrm{z})$. But suppose that the decisionmaker is induced to partition the choice set in the two subsets $(\mathrm{x}, \mathrm{y})$ and $(\mathrm{v}, \mathrm{z})$.

Since the second set presents more variety in terms of destination, it has a positive probability of being chosen. If the second subset is selected, the decision-maker might choose option $\mathrm{v}$, which is not dominated by $\mathrm{z}$, although it is dominated in the original set ${ }^{11}$.

Hierarchical selection and the similarity hypothesis

The view of the choice process as a sequence of constraints is at the base of a class of models which treat choice as a hierarchical elimination process. The elimination process is usually defined over a tree-like representation of alternatives reflecting the structure of their underlying similarity relations. Similarity among alternatives has a meaningful impact on choice: the more similar two options are to each other, the easier they are to compare, and more likely they are to be perceived as close substitutes for one another. Similarity between options has been totally neglected by normative models of choice. Tversky (1972), on the other hand, formulates the "similarity

\footnotetext{
${ }^{11}$ For a classic study of agenda effects on voting behavior, see Levine and Plott, (1977), and Plott and Levine, (1978)
} 
hypothesis", according to which " the addition of an alternative to an offered set "hurts" alternatives that are similar to the added alternative more than those that are dissimilar to it" (Tversky, (1972), p. $283)^{12}$

Let us consider a classic example from Debreu (discussed at greater length in Tversky (1972)).

A consumer is facing a choice between two records of classical music: The first one is a symphony by Beethoven (option B1 in fig. 3a), the second one is a record by Debussy (option D in the same figure).

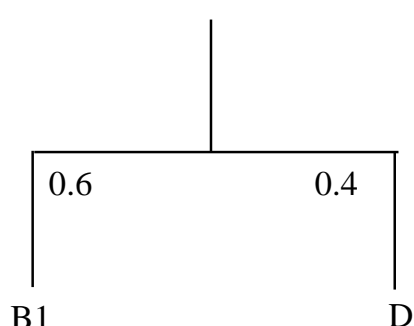

fig. $3 \mathrm{a}$

Now imagine that a third option becomes available, consisting in a different recording of the same symphony by Beethoven (option B2 in fig. 3b).

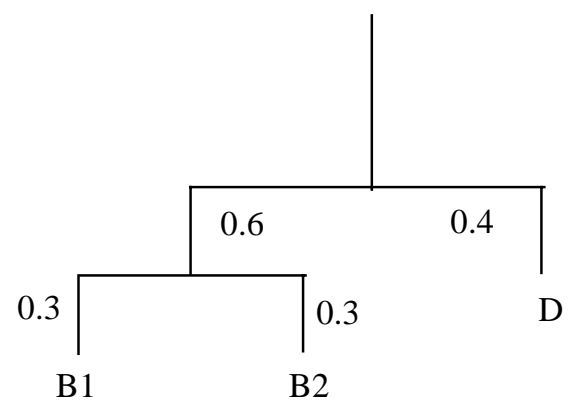

fig. $3 b$

According to normative models, the consumer assigns a utility value to each of the two options, and, assuming she prefers the Beethoven to the Debussy, $u(B 1)>u(D)$. When the third option is

\footnotetext{
${ }^{12}$ Note that the similarity hypothesis is inconsistent with the principle of independence (cf. section iii). In fact, the consideration of similarity relations introduces strong dependence among the elements of the choice set.
} 
introduced, the consumer assigns a utility value to it, which may be equal or greater than either one in the original set, but not such as to reverse the preference ordering already established between B1 and D.

The third option, in other words, might as well have been a Bach, or a Schubert.

On the other hand, it is clear enough that the third option is far more similar to the first Beethoven than to the Debussy. Therefore, according to the similarity hypothesis, its introduction is likely to affect B1 negatively more than D. Let us restate this in probabilistic terms, and assume that the probability of the consumer choosing B1 prior to the introduction of B2 is .6, with the probability of she choosing $\mathrm{D}$ being thus .4 (fig. 3a):

When B2 is introduced in the choice menu (fig. 3b), the consumer who perceives similarity will certainly consider the two Beethoven highly substitutable or even identical so that she might become indifferent on which one to pick. If the last one is the case, then the probability of the consumer choosing B1 will drop to .3, then reversing the previous preference ordering between B1 and D (the probability of choosing D should remain invariant).

Clearly, the high degree of similarity causes the two Beethoven to be perceived almost as a single alternative to be compared with the Debussy.

Tversky and Sattath (1979) propose a probabilistic model called preference tree (or pretree), which represents a further (and more parsimonious) specification of the Elimination-by-Aspects model, and which is consistent with the similarity hypothesis. Each option in pretree is represented as a measureable collection of aspects, and the entire set of aspects is assumed to have a tree structure. At each stage an aspect - corresponding to a branch of the tree - is selected with a probability proportional to its measure, and all alternatives not belonging to the selected branch are eliminated. The process continues until a single option remains. The model expresses context dependence of choice in a way that reflects how structural relations (i.e., similarity relations) among alternatives influence the way options are clustered together in subsets and the sequence in which they are compared. The model is important both from a decision-theoretic point of view, since it relaxes the principle of independence, and from a psychological point of view, because it reflects a choice procedure that is commonly utilized by individuals in several contexts (for example, if one has to choose a post-graduation career, she might first decide between, say, finding a job or going to graduate school; then, if she opts for graduate school, she will decide among several possible fields and then among different schools which offer the chosen program of studies). 
The tree model has been tested empirically for several sets of (admittedly aggregate) data, and it appears to improve goodness-of-fit relative to models which assume independence. Furthermore, all data sets analyzed by the authors show patterns which are consistent with the similarity hypothesis.

To conclude, research on heuristics directly addresses the issue of how human decision makers process information, an aspect which tends to be neglected by the paradigm of "rationality with distortions". While research on biases is typically undertaken by using very simple and stylized choice problems for which the normative theory often provides the "correct" answer, experiments on heuristics are conducted using more complex problems for which no clear "solution" might exist and which might require the processing of a large amount of data. Experimental techniques are likewise more elaborated than simply providing subjects with alternatives and asking them to choose; rather, they often involve also the use of "thinking aloud" procedures and verbal protocol analysis.

As a result, research on heuristics has not received much consideration from economists, since the involved decision processes requires far more cognitive details than usually most of them are willing to incorporate in their models. Too often, in fact, economists' effort to render their theories more behaviorally based has manifested itself through various redefinitions and "refinements" of utility functions - as seen in the previous section, especially in the direction of reflecting consumers' hedonic experiences and their dependence on comparative evaluations.

While such theoretical developments have certainly represented an important step toward psychologically more plausible theorizing, the procedural phase of decision making has been left basically unmodified, and totally identified - by definition - with the coherent fulfillment of the decision maker's goal (which, needless to say, often consists in finding the solution to some optimization problem). On the other hand, experimental literature on heuristics not only emphasizes the "satisficing" rather than optimizing nature of most decision making strategies, trying to build taxonomies according to the degrees of "boundedness" of rationality they embed; it also tries to identify the variegated links between decision strategies and the consumer's goals, which often cannot be reduced to the maximization of one's own utility (however defined).

Among the limits of research on heuristics, which can be broadly seen as deriving from the paradigm developed by Newell and Simon (1971) for the treatment of problem solving, lies the underlying "closed world" assumption, associated with the idea of the decision maker as an 
information processing machine (Holyoak and Spellman, (1993)). The decision maker's goal, whatever this may be, is precisely specified ex ante, the amount of information and knowledge needed to "solve" the choice problem may be large but it is nonetheless delimited, and the choice process itself is viewed as a conscious search through the space of alternatives in the direction of goal achievement.

\section{From evidence to theories}

Interpretation of the evidence on the grounds of Prospect Theory

One of the seminal behavioral contributions to the theory of consumption is in Thaler (1980). There, one finds a discussion of a wide set of circumstances in which several assumptions of the rational models are falsified due to less-than fully-rational behavior. Kahneman and Tversky's Prospect Theory (1979), originally developed as a descriptive model of choice under uncertainty, is then proposed as an alternative framework under which these various anomalies can be accounted for.

Prospect Theory introduces a value function for outcomes, which replaces the traditional utility function used in standard theory and which incorporates the three following behavioral principles:

- Individuals encode outcomes as gains or losses relative to a natural reference point, usually given by their current status or by an aspiration level.

- Losses are valued more heavily than corresponding gains.

- Individuals show a diminishing sensitivity to both gains and losses. That is, adding gains yields a less than proportional marginal utility and adding losses yields a less than proportional marginal disutility. 
The three above mentioned properties generate a function like the one depicted in fig. 4 :

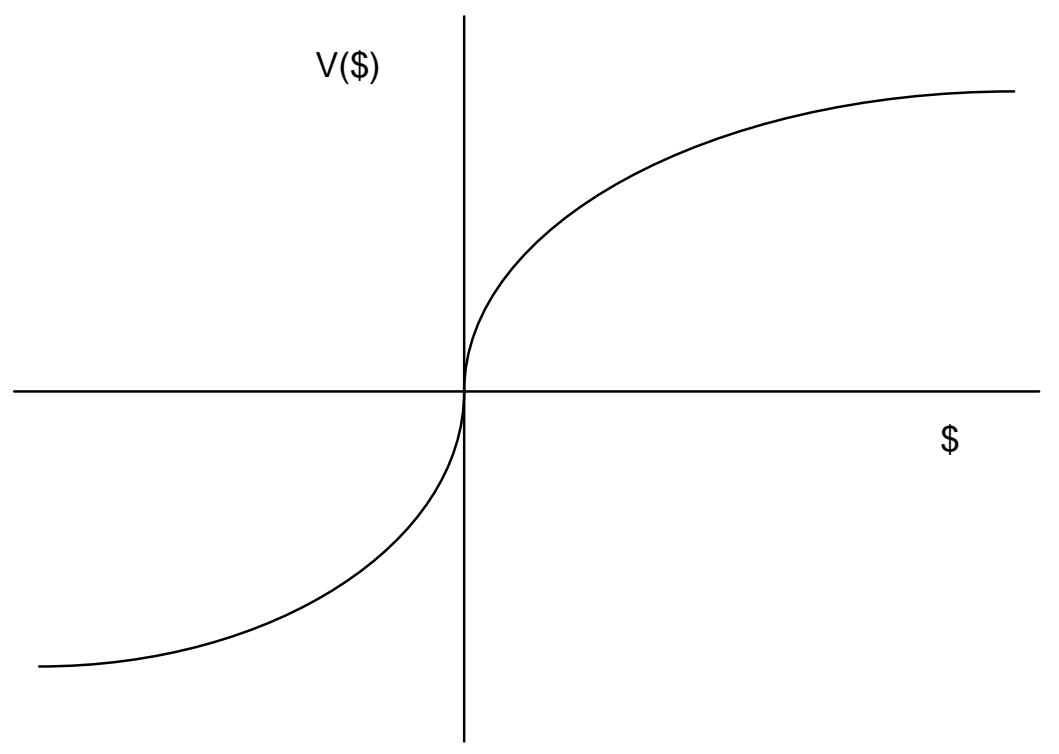

Fig. 4

The authors refer to value instead of utility to differentiate its meaning from the one prevailing in normative models: value in Prospect Theory essentially refers to a hedonic notion of utility.

While Prospect Theory's original purpose was to describe choices among monetary lotteries, its behavioral properties can be extended to deterministic choice as well.

Several anomalies which the standard theory of the consumer would not predict can be explained within the framework offered by Prospect Theory.

Consider the following example, from Thaler (1980):

Mr. $\mathrm{R}$ bought a case of good wine in the late 50s for about $\$ 5$ a bottle. A few years later his wine merchant offered to buy the wine back for $\$ 100$ a bottle. He refused, although he has never paid more than $\$ 35$ for a bottle of wine.

Why did Mr. R refused the offer to sell his wine back? This pattern of behavior is consistent with several experimental findings that show how individuals are reluctant to give up objects once these have become part of their endowment. The difference between what people demand to give up a 
good (the selling price) and what they would be willing to pay to acquire it (the buying price) is caused by what Kahneman, Knetsch and Thaler (1990) call endowment effect.

While standard theory predicts no discrepancy between buying and selling prices, the notion of loss aversion can help make sense of the phenomenon: the most direct effect of loss aversion is in fact people's reluctance to give up what they already have. The disutility of giving up an object that is felt as being part of one's endowment seems to be greater than the utility derived from acquiring that same object.

A closely related effect is the so-called status quo bias, that is the tendency of individuals to prefer the status quo to any change.

Curiously enough, once an object is acquired, it becomes part of the owner's endowment almost instantly.

Kahneman et al. (1990) ran a series of experiments in which an artificial market for coffee mugs was reproduced in a laboratory.

In one of these experiments, subjects were randomly assigned to three different roles. One group, the Sellers, were given coffee mugs and were asked whether they were willing to sell the mugs at each of a series of prices whose range varied from $\$ 0.25$ to $\$ 9.25$. A second group, the Buyers, were asked to state their willingness to buy the mugs for each price of the same set. The third group, the Choosers, were simply asked to choose, for each of the stated prices, between a mug or the amount of money in cash.

Both Choosers and Sellers have to decide, for each price, between the mug and the amount of money in cash, so their situation is equivalent. The median reservation prices in the experiments were $\$ 7.12$ for the Sellers, $\$ 3.12$ for the Choosers, and $\$ 2.87$ for the Buyers. The difference between Buyers and Choosers is negligible, showing that gaining or losing money made a difference. Rather, whether or not subjects had been endowed with the mugs did make a difference, since the Sellers (the mug owners) set up a much higher price (note that mugs were assigned randomly).

Subsequent experiments show that the discrepancy between the two prices diminishes with repeated experience and feedback, although it does not disappear (see Camerer, (1995), and references therein).

A related assumption of economic theory is that out-of-pocket costs and opportunity costs should be equally valued. 
Out-of-pocket costs, however, are typically overweighed relative to opportunity costs.

Knowing that individuals are loss averse can provide one with some insight into this anomaly: assuming that people consider out-of-pocket costs as losses and opportunity costs as foregone gains, then of course the former will loom larger than the latter.

The endowment effect can be considered as a particular example of such asymmetric evaluation: giving up a good belonging to one's endowment is perceived as an out-of-pocket cost (and therefore overweighted), relative to the opportunity cost of acquiring the same good.

A related tenet of economic rationality states that only incremental costs and benefits should affect choice. Sunk costs are historical costs, and should be irrelevant in calculations of future utility values. However, experiments as well as daily experience give us many example in which the principle does not hold ${ }^{13}$.

In consumer settings the sunk cost effect can lead to situations in which "paying for the right to use a good or service will increase the rate at which the good will be utilized, ceteris paribus (Thaler, (1994), p. 11). For example, if the price of annual subscriptions to a swimming pool increases, then, although the number of subscriptions may decrease, those who do subscribe may be likely to go to the pool more often compared to previous years ${ }^{14}$.

According to Thaler, such behavioral pattern makes perfect sense under the hypothesis of loss aversion. However, some additional assumptions have to be made regarding the 'hedonic' evaluation of gains and losses. It is certainly plausible to assume that people do not generally perceive costs (i.e. prices o goods) as losses when the purchase is for immediate consumption. In fact, if this was not the case, under the hypothesis of loss aversion, people would hardly buy anything. Rather, what individuals perceive is only the net gain (or pleasure, in Benthamian terms) resulting from the transaction (if this is positive). Similarly, for goods whose consumption is delayed with respect to the moment of purchase, the cost substained will be perceived as an investment to be repaid when the good is consumed. Only if such consumption for some reason does not occur will individuals perceive the cost as a loss, thus feeling pain. Thaler argues that it is in order to avoid such losses that people are sensitive to sunk costs, and behave in ways that could

\footnotetext{
${ }^{13}$ In organizational decisions, the violation of this assumption can often lead managers to commit resources into failing investments. For the phenomenon of "escalation to sunk costs" see Staw, (1997).

${ }^{14}$ See also Camerer, (1995), and Rabin, (1998), for reviews of the endowment effect and related biases and their implications for aggregate economic behavior.
} 
be judged as self-damaging in some cases. He makes the example of a man who has paid a $\$ 300$ annual subscription to a tennis club and develops a tennis elbow after two weeks. To avoid recognizing the loss of the $\$ 300$, he prefers to keep playing tennis in pain (Thaler, 1994).

According to Prospect Theory, individuals evaluate outcomes as changes from a reference point rather than absolute values. In common purchase situations, the reference point is often given by what consumers perceive as a fair price, or market price for the good they are planning to buy.

The price that consumers perceive as fair for a good varies according to some contextual factors (Thaler, (1985)). Location may be one of these. We certainly expect to be charged very different prices for the same cappuccino according to whether we drink it at a Starbuck's on Main Street or at Cafe' Florian in Venice. In this case the extra money pays the view of St. Mark's Square that we can enjoy in the latter case. But even when we cannot benefit from the extra-value of location or "atmosphere", our perception of a fair price takes these differences into account.

Consider the following scenario:

"You are lying on the beach on a very hot day. All you have to drink is ice water. For the last hour you have been thinking how much you would enjoy a nice cold bottle of your favorite brand of beer. A companion gets up to go make a phone call and offers to bring back a beer from the only nearby place where beer is sold, a small run-down grocery store. He says that the beer might be expensive and so he asks you how much you are willing to pay for the beer. Your friend will buy the beer only if it is less than the price you state". (Thaler, (1985)).

The median price that subjects presented with this scenario were willing to pay was $\$ 1.50$. Another group of subjects were given an identical scenario, with "small run-down grocery store" being replaced by a "fancy resort hotel". The median price was $\$ 2.65$ in this second case (note that the consumer of the beer in this example would not enjoy any of the comforts and amenities of the fancy resort hotel). The difference can be explained by assuming that subjects adjusted their notion of a fair price according to the type of seller (Thaler, (1985)). 
Related experiments further investigate the determinants of reference price formation and the role of framing effects in consumer settings (see, e.g., Diamond and Campbell, (1989), Heath et al., (1995), Jacobson, (1989)).

\section{Mental Accounting}

Thaler (1980) argues that many of the characteristics of deterministic choice can be better understood if we imagine our decisions as the result of some "naive" mental accounting ${ }^{15}$.

Much similarly to real accounting systems operating in firms and households, individuals encode outcomes of transactions according to a mental accounting system by which gains and losses are assigned to specific accounts depending on time or contextual cues.

The rules for the creation of mental accounts are rather flexible and the same transaction can be accounted for according to different principles. Thus, for example, most households group expenditures into different categories (food, clothes, durables, etc.) and potential purchases are then evaluated on the basis of the portion of income assigned to the specific category rather than on the basis of overall earnings.

Many budgetary rules are temporally specific, being usually defined over a weekly or monthly basis rather than, say, over one's lifetime wealth. Sometimes mental accounts can be created as commitment devices to overcome self-control problems.

The existence of mental accounting violates the economic principle of fungibility of money, and has some important psychological and economic implications.

One implication concerns the joint or separate treatment of gains and losses.

According to Thaler (1985) we either integrate or segregate gains and losses associated with an item, before assigning a value to it. Whether the computation of gains and losses results from integration or segregation will influence our overall evaluation of the item in question.

While a general rule cannot be established, in principle individuals will tend to compute outcomes so as to maximize the utility they derive from a transaction.

We know from Prospect Theory that adding gains yields a decreasing marginal utility and likewise adding losses yields a decreasing marginal disutility.

\footnotetext{
${ }^{15}$ See also, e.g., Heath and Sall, (1996), and Bonini and Rumiati, (1996).
} 
Consequently, losses will be generally integrated, so as to minimize their negative impact while gains will be segregated whenever possible, that is whenever the situation justifies the creation of separate mental accounts.

Thus, the price of a kitchen set we decide to buy for our brand new house will be probably integrated with the total price of the house so that the disutility from the loss will be less than if we encoded it separately (but if we buy the kitchen set a long time after purchasing the house, the integration will no longer be justified). On the other hand, winning \$100 and \$200 in two different occasions (for example, racetracks and a poker game) rather than winning \$300 in a single trial will justify a separate evaluation of the two gains, thus making us happier. Clearly, the segregation or integration in these examples suggests the existence of different mental accounting systems which we create and maintain much to our advantage; a single comprehensive account for "house expenditures" in the former case, and two separate accounts, one for racetrack and one for poker in the latter.

The existence of "topic" mental accounts combined with diminishing sensitivity to gains and losses can be illustrated by the following experiment:

Imagine that you are about to purchase a jacket for $\$ 125$, and a calculator for $\$ 15$. The calculator salesman informs you that the calculator you wish to buy is on sale for $\$ 10$ at the other branch of the store, located 20 minutes' drive away. Would you make the trip to the other store? (Tversky and Kahneman, (1981)).

Most subject answered they would; however, very few subjects said they would in another version of the experiment in which the $\$ 5$ savings was relative to the jacket and not to the calculator.

In this case, segregation of mental accounting for the two items makes the same $\$ 5$ saving more appealing in the case in which it applies to a smaller loss: again, the particular shape of the value function can help make sense of this anomaly (see also Thaler, forthcoming).

Thaler (1985) proposes a behavioral model of consumer choice based on the empirical evidence so far described. 
Its model replaces the traditional utility function with the value function from Prospect Theory. In addition, it introduces a notion of reference price and the new related concepts of acquisition utility and transaction utility.

While the former depends merely on the value of an item in relation to its cost, thus being essentially equivalent to the standard concept of utility, the latter depends only on the perceived value of the transaction, which is judged by comparing the price of the item to some reference price. Finally, the principle of fungibility is relaxed in order to reflect mental accounting: goods are assigned specific labels according to their categories, and budget constraints are specified for each category, subject to the general constraint given by income. While the model has not been subject yet to extensive empirical test, it nonetheless represents an ambitious attempt to give formal specification to psychological principles that seem to rule everyday transactions, thus resulting substantially richer than standard theory (incidentally, note that important prescriptive implications for marketing can also be derived from the model).

A more comprehensive illustration of the mental accounting framework, fully inserted within the general hedonic paradigm of Prospect Theory, and used to attempt a reinterpretation of various anomalies and biases from such perspective is in Thaler (forthcoming). The role of mental accounting in saving behavior is discussed in Thaler (1990).

Reason-based choice

Another step toward more "constructive" approaches to decision making are those contributions which, starting from a perspective that further departs from the utility maximization paradigm, focus upon the identification of the determinants of choice that lie beyond individuals' limited information processing abilities. In fact, while the empirical evidence on biases and heuristics shows that choices are often sub-optimal and decision rules are not fully efficient, nonetheless the question of how preferences are shaped remains partly unanswered.

In this respect, not only context certainly matters in modifying the attractiveness of some options relative to others (demonstrating once more the contingent nature of choice), but also one should be able to trace some guiding principles on how attitudes toward alternatives are formed in the first 
place, especially in those cases (indeed the majority in real-life situations) in which the composition of the choice set does not suggest some (absolute or relative) "optimum", and in which information about stimuli is not given in terms of simple lists of attributes and unambiguous numerical ratings (as it is usually the case in many experimental studies on decision making).

Indeed a whole alternative theoretical framework views the individual as making choices on the basis of reasons, which may be internally-based or socially-induced, rather than on the basis of introspection about her own underlying preferences. "It is a fundamental feature of human beings that they have an image of themselves as acting for a reason" (Elster, (1998), p. 66, italics in original).

Reason-based choice analysis is more familiar to fields such as history or political science, and it usually involves reconstructing the decision maker's assessment of "reasons pro and con" different options, the probable (often counterfactual) consequences of alternative courses of actions, and their degree of "social" acceptability.

Shafir et al. (1993) is a seminal attempt to identify overlappings and differences between this approach and the tradition (by and large prevailing in economic theory) of utility maximization, and it investigates the role of "reasons" in decision making through laboratory experiments. Their findings show that, when faced with the need to choose, individuals often seek and construct reasons in order to resolve the conflict and justify their choices, both to themselves and to others. Such reason-based choice behavior can sometimes lead to violations of intuitive principles of rationality. For example, in one of their studies, the authors presented subjects with a choice between two alternative offers of vacation packages over spring break. The two options were carefully constructed so that one presented a series of average features (average weather, reasonable night-life, medium-quality hotel, etc.), while the other presented both very good and very bad features (gorgeous beaches, ultra-modern hotel, very strong winds, no nightlife, etc.). Half of the subjects were then asked to choose one of the two options, while the other half was asked to reject the same two options. Their findings show that the option with very good and very bad features was both chosen and rejected significantly more often than the average option.

Shafir et al. argue that the result can be explained by assuming that when people are asked which option to choose, they tend to focus on the positive features of each option, while when asked which option to reject, they focus on the negative features instead. As a result, an option full of both positive and negative features (an "enriched" option) relative to an option with very few positive 
and negative features (an "impoverished" option) will be both chosen and rejected more often (see also Shafir, (1993a), for additional studies). In other words, the "enriched" option (spot B) offers more reasons, compared to the impoverished option to justify both its choice and its rejection (normatively speaking, the two tasks are formally equivalent) ${ }^{16}$.

Some of their related findings concern choice under conflict. People often experience a certain amount of conflict when making choices. While this fact certainly appeals to everybody's intuition and experience, note that conflict is completely neglected by normative models of decision-making, which assume that individuals are always able to assign utility values to alternatives and select the highest-valued option.

Again, contrary to normative rules, in everyday situations individuals are not always able to assign values to alternatives, they may not know how to tradeoff attributes (price against quality, for example), and when faced with a choice between two options that seem equally attractive, they often experience conflict ${ }^{17}$. In this respect, conflict has a significant impact on choice, since it can induce individuals to delay decisions, maintain the status quo, or seek additional information incurring costs.

Again, the search for compelling reasons or arguments in favor of one alternative can constitute a useful device.

Tversky and Shafir (1992a) ran some experiments in which they asked two different groups of subjects to imagine wanting to buy a $\mathrm{CD}$ player and passing by a store that is having a 1-day clearance sale: The first group (low conflict) was asked to choose between buying a very popular SONY Compact Disk player offered at $\$ 99$, or defer the purchase to learn more about other models available. The second group (high conflict) had to choose among the same Sony player, a more sophisticated AIWA player priced at $\$ 169$, and the same option to defer choice.

While in the first (low conflict) condition the majority of subjects $(66 \%)$ decided to buy the CD player, and only $34 \%$ of them decided to wait, in the high conflict condition, only $27 \%$ of the subjects decided to buy the same CD player, and $46 \%$ of them decided to defer the purchase.

\footnotetext{
${ }^{16}$ There is a close analogy between this finding and related findings in the domain of similarity judgments. Studies (Tversky and Gati, (1978) have shown that when subjects are asked to judge how similar two objects are to each other, they tend to focus on the objects' common features, while if asked to judge how dissimilar the same two objects are, the focus on each object's distinctive features instead. As a result, in some cases the same two objects may be judged both very similar in similarity judgments and very dissimilar in dissimilarity judgments. ${ }^{17}$ For a choice framework based on conflict resolution, see Hogarth, (1987).
} 
The results indicate that individuals are more likely to buy a product when they only have one attractive option available. In the high conflict condition, the presence of the two options involves a conflict-triggering tradeoff. The conflict may not be easy to resolve, and many subjects thus prefer to wait.

The low conflict condition, on the contrary, presents a unique very attractive alternative, and therefore subjects are more inclined to choose it.

As the authors point out, these results also seem to demonstrate that, as conflict is often hard to resolve, having more choice does not always make agents better off, contrary to both economic theory assumptions and common-sense intuition.

In other situations the presence of an additional option may have a positive effect on conflict resolution.

Tversky and Shafir presented a third group of subjects a choice between the same popular SONY player on sale for $\$ 99$, an inferior AIWA player for the regular list price of $\$ 105$, and the option to defer choice to learn about other models. In this example the second option is dominated by the first one, since it is inferior in quality and costs more. Therefore, there is no conflict involved in the comparison between the two alternatives, and the presence of the inferior option gives subjects a compelling argument to choose the superior one. Consistently with the hypothesis, the large majority of subjects $(73 \%)$ decided to buy the SONY player in this situation, compared to the $27 \%$ of subjects who chose the same option in the high conflict condition.

Shafir et al. (1993) also argue that several context effects such as the attraction effect (cf. section iii) can be explained in terms of reasons.

The initial choice between two options that present a tradeoff is not trivial and may activate a certain amount of conflict in the decision-maker, since there are no compelling arguments in favor of one or the other.

Adding an asymmetrically dominated alternative can then resolve the conflict by providing a reason to choose the option that dominates it. Simonson (1989) demonstrated that the attraction effect was significantly stronger when subjects anticipated having to defend their decision. In this condition, the dominant option looked like the easiest to justify.

Relatedly, extremeness aversion can be accounted for by assuming a "reason-seeking" behavior: in the presence of options with extreme values on different dimensions, in fact, a middle option represents a good compromise which may be more easily justifiable than the extreme ones. 
Similarly, tradeoff contrast can be explained by assuming that people who experienced a certain price-quality tradeoff in the past, when confronted with a better tradeoff (in which additional quality "costs" relatively less), they have a good reason to select the high quality option for its relative convenience.

Another striking result was found by Tversky and Shafir (1992b) in the domain of decision-making under uncertainty.

University students were presented with the following dilemma: one group of subjects was asked to imagine having just passed a tough qualifying examination and being offered the chance to purchase a very attractive 5-day vacation package in Hawaii: students then had the choice between:
a) buying the vacation package
b) not buying the vacation package
c) paying a $\$ 5$ non-refundable fee in order to retain the rights to buy the vacation package at the same exceptional price the day after tomorrow (Tversky and Shafir, 1992b)

A second group of subjects was given the exact same dilemma except that they had to imagine having failed the exam. The three final options were the same as in the first group.

More than half (54\%) of the subjects chose to buy the vacation package in the pass version and even a larger percentage (57\%) did the same in the fail version.

A third group was then presented the same choice except that now the result of the exam was not known. The three options were:
a) buy the vacation package
b) not buy the vacation package
c) pay a $\$ 5$ non-refundable fee in order to retain the rights to buy the vacation package at the same exceptional price the day after tomorrow-after you find out whether or not you passed the exam (Tversky and Shafir, (1992b)).

In this last version, $61 \%$ of subjects preferred to pay the $\$ 5$ fee and wait to find out whether or not they had passed the exam.

Tversky and Shafir suggest that the result can again be explained in terms of reasons for choice. The students in the pass and fail versions have definite reasons, although different, to buy the vacation 
package (a reward in the first case and a consolation in the second case). Most of them, in fact choose to go to Hawaii. But when the outcome is not known, the lack of a clear reason for deciding to go on vacation makes the decision more difficult. As a result, the majority of the students prefer to pay and wait for information which, although irrelevant, (since they would choose to go to Hawaii in either case), provides them with a definite reason for choosing (Shafir et al., (1993)).

In this example, a reason-driven behavioral pattern is combined with a general difficulty of individuals at reasoning through disjunctions, that is at correctly exploring and simultaneously evaluating the consequences of different branches of a decision tree (see also Shafir, (1994)).

An implication of such result is that individuals in several situations may actively seek and pay for information that is virtually irrelevant in terms of its actual effects on their final decisions.

The phenomenon of reason-based choice is tightly linked with the issue of social accountability of decisions. While reviewing the literature on social accountability is beyond the aim of this paper, we recommend Tetlock (1992) for an insightful discussion.

A contingent framework

In an attempt to provide an integrated approach to decision making, Bettman, Luce and Payne (forthcoming) propose a "contingent framework" for understanding consumer choice, reviewing and explaining empirical evidence in that light.

Their main point is the inherently constructive nature of both consumers' preferences and choice processes.

Preferences are constructed because individuals often lack the knowledge and ability to develop well-defined preferences, valid a priori. In addition, choices are usually made in order to accomplish multiple goals. The main goals which determine choices according to the authors are: maximizing the accuracy of a choice, minimizing the cognitive effort it implies, minimizing the experience of negative emotion associated to a choice, and maximizing its justifiability to themselves or to others. The relative importance assigned to each goal will be determined by a variety of contingent factors, including the importance of the decision, ambiguity of the feedback relative to the degree of accomplishment of each goal, and the degree of accountability for the decision. Given an array of different goals, then choice strategies will then be judged in their advantages and disadvantages with respect to reaching different goals in a given situation. The 
consumer will select the choice strategy that maximizes the advantages with respect to the most important goal in the specific decision task.

The authors introduce a measure for accuracy (based on each strategy's relative distance from the weighted adding model) and effort (measured by the number of elementary information processes each strategy requires) according to which strategies can be valued, and they make predictions about when a set of major strategies will be used according to the consumer's relative preference for accuracy over effort.

They subsequently specify situations in which one set of goals is likely to result more salient than others; more specifically, situations where accuracy and effort goals predominate and situations in which, on the contrary, maximizing the ease of justification or minimizing negative emotion might prevail.

Several other empirical facts like the ones described in the previous section, are then re-interpreted from this perspective.

The authors' framework is extremely rich as it explicitly addresses the problem of both consumers' goals and the impact of emotions on choice ${ }^{18}$. The interpretation of goals in this view is consistently diverging from the one stemming from standard utility theory and also from the related multiattribute utility models (MAUT). In fact, while MAUT postulate conflicting goals guiding the decision maker simply by identifying them with the assignment of partial utility values to single attributes ("how much more do I value safety in a car compared to convenience?") whose weight on choice is eventually resolved in a tradeoff, goals in this contingent framework are essentially metagoals ("do I really want to tradeoff safety against money?"), which, much more than just determining overall utility values, intervene in shaping preferences, selection of choice strategies and, of course, outcomes.

Several aspect still remain unspecified and need further investigation, however. Among others, this framework does not address the nature of problem representations and the principles which govern their formation. This is indeed the central concern of the theories which explicitly address the nature of mental representations.

\section{Mental models in consumer behavior}

\footnotetext{
${ }^{18}$ The role of emotions in choice behavior is an issue for long neglected by economists. However, see Elster, (1998), for an assessment of the role of emotions in economic behavior.
} 
Most "high-level" cognition involves some process by which subjects form and modify mental representations in order to understand and manage a reality which is generally too complex and uncertain to be grasped in its entirety (see also the discussion in Aversi et al., (1999), this volume). Studying mental representations is crucial in the understanding of aspects which go from concept formation, to memory, inference and judgment. That is why mental representations have been a focal interest across different branches of psychology, cognitive science, philosophy and artificial intelligence.

"A crucial question for theories of thinking concerns relevance: How do people access and exploit knowledge relevant to their goals when drawing inferences, making decisions, or solving problems?" (Holyoak and Spellman, (1993), p. 293).

The answers to this question are diverse: studies on reasoning have seen recent theories reject the traditional rule-based approaches and claim that human inference is based on (often incomplete) mental models of the premises (Johnson-Laird, (1983)). Students of artificial intelligence have on their part tried to identify and formalize the rules that govern the structure of representations both in human and artificial organisms (Holland et al., (1986)). Studies on memory and cognition have shown that information about the world is usually stored and retrieved according to hierarchical or cluster-type structures of categories (Rosch, (1978), Lakoff, (1987)).

Economics has paid very little attention to these themes (an exception being Marengo and Tordjman, (1996), on the evolution of mental models in financial markets). The reasons for that probably have to do, among other things, with the particular nature of the research. It is rare to derive in this vein simple formal theories which make sharp predictions and which can be readily translated into a set of coherent axioms.

Inherent to all disciplines that deal with the representation of knowledge is the idea that humans face an environment which is complex, multifaceted, only partly understood and constantly changing. Complexity and novelty are hard to translate in formal theories; hence mathematicallybased social sciences have largely attempted to skip the problem by relying on a sort of generalized "small world assumption" (Savage, (1954)), which postulates a finite set of possible states and related priors (in consumption theory the set of states is composed of the consumption bundles available to the consumer) present ex ante in the mind of the agent and whose truth or falsity the 
agent learns as a consequence of a Bayesian process of inference (or, mutatis mutandis, whose utility maximizing bundle is selected by applying an optimization algorithm; see Dosi et al.,(1996), for a discussion).

In this respect, even most of what now is called behavioral economics implicitly maintains this fundamental assumption about the world it tries to model.

On the contrary, in a world with radical (not probabilizable) uncertainty, and constant flows of innovation which render the set of possible states notionally infinite, it is a plausible conjecture that individuals try to cope by mapping the structure of the environment into fuzzy (and often partial) mental isomorphisms from which inductive generalizations are drawn through heuristic processes.

"Although mental models are based in part on static prior knowledge, they are themselves, transient, dynamic representations of particular unique situations. They exist only implicitly, corresponding to the organized, multifaceted description of the current situation and the expectations that flow from it" (Holland et al., (1986), p.14).

Notwithstanding the relevance of mental models in most aspects of human cognition, the issue is still largely unexplored with respect to decision making, especially by those behavioral scientists who operate within the "deviation from perfect rationality" paradigm. On the other hand, it is sufficient to take even a short look at journals of marketing and consumer behavior to realize that the amount of experimental and empirical studies devoted at understanding consumers' representation of knowledge is enormous.

The following section briefly lists some of these contributions, which specifically address the problem of how relevant knowledge is encoded, organized and elicited in a cognitive system. Interrelations with decision making are highlighted.

Focusing effect and mental models in decision making

A basic tenet of normative models of choice states that the decision maker is always able to evaluate all available alternatives: In real-life situations, however, this is rarely the case. The first, and most obvious reason has to do with the fact that individuals only know a subset of all the potentially feasible options. The second reason is more subtle and has to do with the way our mind is structured. Experiments have shown that individuals in some cases may simply fail to consider their entire space of alternatives, unless somewhat induced to do so explicitly. An analogous 
phenomenon emerges in the context of reasoning, where the failure to consider all the relevant dimensions of a problem leads individuals to commit systematic fallacies.

In a seminal study of the interaction between reasoning and decision making, Legrenzi et al. (1995) asked a group of subjects to imagine being offered to choose whether or not to go to the movies, knowing the experimenter could provide them with all the information they needed in order to decide.

The majority of subjects asked several questions about the movie, totally neglecting the "or not" part of the choice: That is, subjects focused on getting more information about the activity that had been explicitly mentioned ("going to the movies"), completely failing to consider any alternatives that had been left implicit in the proposal (for example, going to theater, to the opera, and so forth).

This is a simple but powerful example of the so-called "focusing effect", a phenomenon initially detected in the area of deductive reasoning which seems to depend on the partiality of the individuals' mental encoding of information.

Of course, one possibility is always to place this phenomenon under the broad and somewhat residual heading of "distorsions and imperfections in information processing". An alternative, in our view much more promising, is on the contrary to begin to explicitly disentangle the "cognitive blackbox".

On the grounds of experimental evidence on deductive and inductive inference, Johnson-Laird (1983) has proposed an approach to logical reasoning based on the idea of mental models. According to his theory, originally aimed at explaining human deduction (see also Johnson-Laird and Byrne, (1991)), individuals do not perform reasoning tasks by applying syntactic rules. Rather, they reason by constructing mental models of the situation expressed in the premises of a problem, enriching them with their general knowledge about the world. They subsequently derive a tentative conclusion on the basis of such models, and try to build counter-examples of models in which the conclusion might be false. If no such models can be found, they assume that the conclusion is correct. Such semantic (rather than syntactic) process can lead individuals to make both correct and incorrect inferences, mainly depending on how the model-construction phase is performed. For example, studies have shown that individuals have difficulties in explicitly representing premises stated in form of negation, or in modeling information which is left implicit but can nonetheless be immediately derived from the premises. Such difficulties in "fleshing out" all the relevant states of affairs can be generalized to the domain of decision making, if one makes the hypothesis (indeed, 
quite plausible), that many decisions we make in daily life depend on some form of reasoning ${ }^{19}$ (for example, seeking and encoding information, making inferences, selecting and applying choice criteria, etc.). "If individuals reason in order to make decisions, then phenomena that occur in reasoning should occur in making judgments and decisions" (Legrenzi et al., (1993), p. 38). An extension of the "focusing" effect to consumer choice concerns the consumer's treatment of information about products. Experiments (Kardes et al. (1990)) have shown that consumers tend to completely neglect missing information about a product, even in those cases in which the information, if present, would have a large impact on the consumer's evaluation process and subsequent choice. Slovic (1972) suggests a "concreteness" principle to explain such phenomenon.

\section{Schemas and scripts}

Interest in the study of mental representations among consumer researchers has largely progressed as the shortcomings of the information processing approach have been increasingly recognized. The acknowledged partiality of an approach which sees the consumer as a boundedly rational, but nonetheless conscious and analytical problem solver, has focused the attention on the identification of the basic cognitive structures which shape preferences, attitudes, and in turn consumption behavior, according to an approach which may be loosely defined as top-down, in contrast with the piecemeal, bottom-up approach of the information processing view. According to the top-down view, problem solving in general and decision making in particular is tightly linked to higher-level knowledge structures and frames that shape the entire perception of the task and subsequent "performance" (Gardner, (1985); see, e.g., Nakamoto, (1987), for a discussion of these different approaches to consumer research). The key feature is that such link cannot be entirely reduced to some computational and analytical encoding procedure, but, on the contrary, it is at least partly "holistic" and "global" in nature (see, e.g., Cohen and Basu, (1987)). In consumer behavior, this traduces itself in the fact that information about products is structured in terms of larger "chunks", which are stored in memory as relatively unitary entities coupled with global evaluations or affective responses which often cannot be decomposed in their single elements (the opposite of what is postulated, by, e.g., multiattribute utility theory). For example, consumer researchers have

\footnotetext{
${ }^{19}$ Interactions between reasoning and decision making are still to be largely tapped. For a critical assessment and review, see Johnson-Laird and Shafir, (1993).
} 
identified two basic modalities for stimuli evaluation: piecemeal processing and category-based processing (Fiske, (1982); Fiske and Pavel, (1986)), which are used, alternatively or in combination, depending on variables such as the level of expertise, and the degree of matching between information encountered and previous expectations (Sujan, (1985)). While the former processing rule recalls the bottom-up, computational view (consisting in attribute by attribute evaluations which are combined according to some compensatory or sequential strategy), the latter usually involves a much more intuitive and (often automatic) process of instance-class comparison and transfer to the instance itself of some category-based global evaluations, much more in tune with the top-down approach above mentioned. The key empirical question then concerns precisely the identification of the characteristics of such knowledge structures and their role in judgment and evaluation. In this vein, both cognitive and social psychology offer a wide range of conceptualizations: among the most widely applied in consumer research are the notions of schemas, scripts and categories.

Schemas are generally represented as hierarchical structures for the encoding and storage of information, with higher levels including more generic knowledge and lower levels containing more specific information about particular instances of a concept (see, e.g., Taylor and Crocker, (1981)).

Researchers often distinguish schemas as organized structures having both spatial and temporal dimensions, from categories, usually intended as taxonomic classifications of objects. When the temporal dimension is relatively more prominent, schemas are usually referred to as scripts, intended as stereotypical sequences of events with associated a set of routinized expectations and rules of behavior. For example, a script for a typical activity such as "going to the restaurant" will activate both a series of expectations (we expect the waiter to come to our table and take orders), and a repertoire of pre-stored action sequences (sitting at the table, ordering meals, eating, etc.).

The key role of schematic structures of information is to provide expectations about a class of events, which are then translated to novel instances, whenever encountered. The role of schemas, in short, is both providing an interpretation of stimuli and guiding inference, e.g. providing pre-stored expectations in substitution for missing information.

With respect to product classes, studies have shown that consumers, through familiarity and expertise, develop schemas of expectations which may include assessment of average values for each relevant attribute, determination of the attributes' relative importance, and the degree of 
variability of different brands around some median or modal value (Meyers-Levy and Tybout, (1989); Peracchio and Tybout, (1996)). The degree of congruity between schema-based expectations and experience with a product is crucial in the post-trial evaluation and classification. Low degrees of congruity may be likely to activate new schemas ex novo (see, e.g. Stayman et al. (1992), and Sujan and Bettman, (1989)), while high degrees of congruity are likely to result in the product assimilation into pre-existing schemas.

The role of schema congruity in evaluation is also crucial: studies (Fiske, (1982)) have shown that an instance is rated as more preferable when it is partly inconsistent with schema-expectations that when it is highly consistent. However, further investigation is needed.

\section{Categories}

The notion of category has known a wide use in the area of cognitive science, particularly in relation to domains such as concept formation, learning and memory. Categories and categorization processes also play an essential role in consumer settings. Most advertising efforts by firms to communicate specialized "positionings" for their products in the market may be read as attempts to influence consumers' judgments of category membership for those products.

Among the various models of categorization that can be found in cognitive psychology, the prototypical model is by and large the most widely applied in research on consumer behavior. Let us start with some brief remarks about the model, before referring more in detail to its applications to consumer behavior.

According to the prototypical model (Rosch, (1978)), categories serve two basic functions in human cognition: the first is a function of cognitive economy. By classifying a stimulus as instance of a given category one is able to retrieve a considerable amount of information about that particular stimulus. One purpose of categorization is thus to reduce the infinite diversity of the environment to cognitively tractable proportions. The second principle of categorization pertains to the structure of the perceived world. Combinations of attributes in the perceived world do not appear uniformly, but according to a highly correlational structure that forms natural discontinuities (so, for example, the pair of attributes wings and feathers has a higher probability of co-occurring compared to wings and 
fur). Categories can be thought of as concepts or images reflecting such discontinuities in a cognitive system.

In the prototypical model, categories are structured according to two levels.

The vertical level differentiates categories according to their degrees of abstraction (for example, the categories German shepherd, dog, mammal, animal, living being are situated at increasing abstraction levels), thus forming hierarchical structures characterized by inclusiveness relations. Categories at higher levels (or superordinate categories) include instances that share only a limited number of general and abstract attributes and otherwise differ in many respects (both a giraffe and Bill Clinton can be categorized as living beings), while categories at lower levels (or subordinate categories) contain instances that usually share a high degree of similarity (all German shepherds are likely to resemble each other).

Various experiments (Rosch et al., (1976)) have shown that a particular level exists at which individuals normally tend to categorize items: Such default level of categorization (the basic level) corresponds to the concrete objects.

For example, if one is shown a picture of a chair and he is asked to name the object he is looking at, his most likely answer will be "a chair" (basic level), although in theory he might as well respond: "It's a piece of furniture" (superordinate level), or "it's a red, plastic, office chair" (subordinate level). The particular "salience" of the basic level in dividing the perceived world into separate entities derives from it being the level which allows both the greatest intra-categorical homogeneity and the greatest inter-categorical differentiation. Besides, experiments have demonstrated that the basic level is the level at which children first learn to perform categorization tasks (Mervis and Pani, (1980)).

The horizontal level corresponds to varying degrees of typicality. In this sense, what distinguishes the prototypical and all subsequent models from the classical (or Aristotelian) view on categorization is the absence of clear-cut inter-categorical boundaries. Category membership, rather than being a binary variable, is a matter of grade: instances of the same category are generally perceived to be differently typical or representative of that category (robin, for example, is normally perceived as a more typical bird than penguin). Each category has a graded structure that corresponds to the different degrees of typicality of its members, with more typical instances lying at the core, and less typical ones at the borders (Rosch and Mervis, (1975)). 
Definition of prototypicality in Rosch's model is closely associated with the notion of family resemblance, an idea originally introduced by Wittgenstein (1953). Family resemblance of an instance to its category is higher, the higher the number of attributes it shares with members of the same category, and the lower the number of attributes it shares with members of contrasting categories (note that Tversky (1977) provides a formal definition of prototypicality in terms of family resemblance using the contrast model of similarity (cf. section iii)).

Prototypes in other words are formed according to the same two principles that govern the formation of categories themselves: the highest amount of category information and the maximum inter-category differentiation are achieved in correspondence of prototypes. In addition, prototypical members share a number of interesting properties: Mervis and Rosch (1981) has shown that individuals tend to classify prototypes more easily and faster as members of a category than nonprototypes, and tend to use prototypes more often than non-prototypes as cognitive reference points in comparisons (Rosch, (1975b)). Furthermore, prototypes are often perceived to possess a greater number of valued attributes (Ward and Loken, (1988)).

The notion of typicality is particularly relevant to consumer research. Given the evaluative context of most product categorization tasks, category-based attitudes and preferences are likely to be maximally activated in correspondence of prototypical members. Therefore, for example, similarity of a product to some prototypical exemplar may greatly determine the product's degree of acceptance among consumers.

In fact, it seems to be established by a number of studies in marketing and consumer behavior that a positive relationship exists between typicality and preference in a variety of product categories (Ward and Loken, (1988); Nedungadi and Hutchinson, (1985)). Hence the great importance of typicality as a measure of a product's expected success in the market.

The vertical level: hierarchies and decision rules

Categories are mentally organized as hierarchical structures with different levels of abstraction. In much the same way, product categories can be ordered according to their degree of abstraction and inclusiveness relations (Howard, (1989)). 
Product hierarchies are important when studying sequential heuristics or agendas. In fact, this class of decision rules is characterized by partitions of the choice menu and a sequential elimination of subsets. In some cases, the structure of the product hierarchy can provide the natural basis for the partition criterion. Typically, the consumer first selects the higher level (or superordinate) category and then proceeds along the tree representation of alternatives to select among subcategories (see, e. g., Devetag et al., (1996)).

Levels of categorization have a direct impact on choice heuristics, in that they partly determine which class of choice strategies will be used in a particular decision task. Choices that involve products belonging to the same (basic or lowel level) category are more likely to involve attributeby-attribute comparisons, while choice strategies to select among options belonging to different categories may be more constructive in nature and rely on processes by which concrete attributes are transformed into more abstract dimensions on which a comparison might be possible (Johnson, (1984)).

Often what distinguishes choices among comparable (same category) options from choices between noncomparable ones (different categories) is the availability of pre-established decision criteria in the former case versus the need to contruct them in the latter case (Bettman and Sujan, (1987)). Sometimes options may belong to the same superordinate class, or they may be compared on the basis of how well they satisfy the same goal (Johnson and Fornell, (1987); Johnson, (1989)).

Individuals often tend to compare products on the basis of abstract attributes even when a comparison on more concrete attributes is possible (Corfman, (1991)).

The horizontal level: prototypes and preference formation

The relevance of prototypes as organizing principles around which many processes of judgment, comparison, perception and attitude formation are constructed has been pointed out in several psychological studies, which, considered jointly, highlight striking similarities in the results (see Kahneman et al, (1998)).

Judgments of probability are often conducted on the basis of how representative an instance is of a certain class (Tversky and Kahneman, (1983)). Perceived typicality is also the basis of individuals' responses in several category-based inductive arguments (see Osherson et al., (1990); Rips, (1975); 
Shafir et al., (1990b); Smith et al., (1993); ). Attitudes towards objects or collections or similar objects are likewise shown to depend on perceptions of prototypicality (Kahneman et al., (1998)). In consumer choice settings, typicality matters a great deal in shaping perception of product classes, expectation formation and, of course, preferences. Some examples of such typicality-driven preference patterns can be found to manifest themselves at the market level.

If someone is asked to recall a brand of soft-drink, Coca-Cola will be in most cases the first one to come to mind. In the US, the verb "to xerox" a document comes from a famous brand of copy machine. Samsonite has by now become a synonymous for a rigid suitcase typically used for air travels.

What these examples all have in common is that being the first entrants in a new market has given these brands a special prominent position in the consumers' minds: some brands have actually become synonymous for the entire product category.

This particular prominence traduces itself in a greater market share that first entrants in a market usually have and keep over time, even when better competing products become eventually available (Kardes et al., (1993)).

As traditional economic explanations, such as entry barriers and consumers' switching costs are not sufficient to give full account of the magnitude of the pioneering advantage, another, more cognitive explanation has been advanced which applies the notion of prototypicality.

The first entrant in a new market has a great impact on the process of preference formation, especially in case of innovative products.

The pioneer is often the first, and initially the only source of information that the consumer has on the new product category: This uniqueness gives the pioneer a great cognitive advantage over the competitors, in that it structures the perception of the product category in the consumer's mind and it establishes the "ideal" composition of attribute values for the entire class. Besides, the pioneer has a high probability of becoming the prototype of the new category, and, being the process of category formation for product classes often choice-oriented, a high degree of prototypicality is likely to be associated with a high degree of preference (Carpenter and Nakamoto, (1988)).

Moreover, the prototype usually becomes the standard of comparison against which all new competitors are valued.

Various experiments have shown the impact of order-of-entry effects on preferences; the first mover's advantage seems to be highest when product quality is ambiguous and related more to 
symbolic aspects (such as status, prestige, etc.) than to technical ones (Carpenter and Nakamoto, (1989)). In addition, pioneering brands are usually recalled from memory faster and more frequently than followers, hence the pioneer is more likely than followers to enter the consumer's mental set of options to be considered for purchase (Kardes et al., (1993)).

\section{Alternative views on categorization}

While the prototype model of categorization, based on typicality and family resemblance as measures of membership degree, is the most widely used in the marketing and consumer psychology literature, other models have been given consideration, in which particular relevance is given to context in defining category membership (see Cohen and Basu, (1987)).

While classic prototype models consider categories as relatively stable and de-contextualized entities, Barsalou (1983) adopts a much more contingent and subjective perspective on the issue of categorization.

According to his view, categories often exist in relation to a goal. Examples may include "things to take to a picnic", or "things to eat on a diet", or others. Note that in this type of categories, membership is not defined on the basis of similarity, but in relation to the degree of satisfaction of the same goal.

Such goal-derived categories are much less stable and have much fuzzier boundaries than "natural" (or prototype) categories. They often emerge in response to contingencies, and they may include members of different natural categories.

Most of the categories that we consider in purchase situations are partly goal-derived in nature. The notion of prototype differs too according to the presence of absence of a goal (our prototype of the natural category chair may be very different from the prototypical - or ideal - chair that one has in mind when considering the purchase of new furniture for the living-room). Experiments show that the former generally depends on the degree to which an instance possesses commonly shared attributes within the category, while the latter depends on judgment of the item's contribution to goal achievement, and on the frequency with which the item has been encountered as a member of the category in the past (Barsalou, (1985)).

More recent contributions further stress the relevance of context-dependent factors in consumers' category judgments (see Cohen and Basu, (1987); Thompson, (1989)). 
What emerges from these studies is the fact that categorization in consumer settings distinguishes itself by being essentially functional to specific goals and evaluation purposes. Therefore, classifications of products into categories may depend on objective, feature-based comparisons as well as on evaluative needs (for example, wine may be either classified according to the subsets of red and white, or, alternatively, in low quality and high quality, or possibly both criteria together).

"Since consumers' interaction with various products usually occurs in an evaluative context, categorization and evaluation may be interwined from the very formation of the category. Subsequent affective responses to products, then, may be derived from their identification as a member of a particular category" (Cohen and Basu, (1987), p. 456).

An interesting model that belongs to the class of probabilistic models of categorization has been developed by Holland et al. (1986). According to the authors, categories are formed by clusters of rules organized in default hierarchies. Each stimulus we encounter is first classified according to higher level categories, which will provide us with "default" expectations, that is expectations that are considered valid so long as they are not contradicted by more specific information about that stimulus. So, for example, knowing that $\mathrm{X}$ is a bird will activate a set of default expectations about $\mathrm{X}$ ("it has wings, it flies, and so forth"). If subsequently we are told that $\mathrm{X}$ is a penguin or an ostrich, more specific expectations will be activated which contradict some of the default ones ("penguins and ostrichs do not fly"). The approach underlying the model of default hierarchies is more pragmatic and linked to problem solving compared to Rosch's model, even though it retains many of its features (namely, the organization of categories in hierarchical structures and the centrality of prototypes).

Categorization and decision processes: some interconnections

When new products appear on the market, the first information available to consumers is highly critical in determining their judgments of category membership for those products.

Howard (1989) considers the whole categorization process and the subsequent purchase decision as a problem solving procedure having different levels of difficulty and complexity in correspondence of each period of the product life cycle. Usually the first stage (extensive problem solving) corresponds to the phase of introduction of a new product in the market, and requires the greatest cognitive effort. Consumers initially do not have familiarity with the new product and, since they 
have to form a concept of it, they tend to assimilate it to existing categories. Therefore, properties of the selected categories will be thought to characterize the new exemplar as well.

Subsequently, through usage experience, consumers develop new ad hoc judgment criteria to evaluate the product and to differentiate it from existing categories. This is the phase during which a new category gradually develops.

The second stage (limited problem solving) is the one corresponding to more advanced phases of the life cycle. Since evaluation criteria have already been established, consumers must only position each new brand in the space defined by the relevant attributes. Cognitive effort is limited at this stage.

Finally, the last stage (routine problem solving), occurs at the maturity level of the product life cycle. The consumer in this phase adopts quasi-automatic decision rules that require the minimum effort (e.g., simple rules such as "buy the brand you bought last time", or buy the brand that is most easily available at your usual store", etc.)

Categorization has also a crucial influence on the process of information acquisition. Experiments (Ozanne et al., 1992) have shown that the degree of congruity between a product and expectations associated to its category greatly determines consumers' search of additional information regarding that product. If there is a partial mismatch between the product characteristics and category expectations, the search for information will continue until the mismatch is resolved either by including the product in the initial class or by activating a new category for it.

Further connections between categorization and decision making have not been fully uncovered and nonetheless deserve more extensive investigation. An area to explore regards the incompleteness of representations. For example, the neglect of opportunity costs in consumer choice (cf. section iv) may not depend only on the "hedonic" asymmetric treatment of gains and losses entailed by Prospect Theory, but also on the failure to consider possibilities that lie outside the decision maker's range of more "salient" options. In fact, taking into account opportunity costs presupposes being able to actively imagine alternative uses of money, which may not be in the decision maker's habitual cognitive repertoire, unless triggered by some contingent occurrence.

Recent studies have demonstrated the importance of context in determining category membership for products. Clearly, the way we classify items depends among other factors on the context in 
which the task is performed and on its goals. Therefore the categorization of a product may be subject to all sorts of manipulations of contextual factors, much like in the case of choice.

The definition of a basic level for product categories is itself even more problematic than for socalled natural categories. What is the basic level for the category "computer"? Are laptop and desktop computers further specifications or basic level categories themselves? Various reasons suggest that levels of abstractions themselves are rather flexible and contingent on the particular nature of the task and of the environment (see Holland et al., (1986)).

Finally, prototypicality for product categories still needs further investigation, especially in relation to processes of judgment and choice. Experiments have demonstrated the role of typicality in determining a series of reasoning fallacies. More research should be aimed at testing if typicality affects decision making in a way which may result in violations of normative rules. Given the comparative nature of most human decision processes, and given the centrality of prototypes as cognitive reference points, it seems compelling to look for violations of normative standards given by exemplar-prototype comparisons in choice tasks (for a recent study on prototype-based judgment "fallacies" in dollar responses to public issues, see Kahneman et al., (1998)).

Study of categorization would be useful also in order to understand phenomena like mental accounting. In fact, the criterion by which mental accounts are created seems to be given by a categorization of the different types of expenditures according to temporal or situational constraints. Such categorization responds to pragmatic as well as "hedonic" needs. Certain types of partition criteria, however, are likely to result more salient than others for most individuals. For example, is there something corresponding to a "basic level" used for budget allocation? A better knowledge of categorization in such contexts would shed more light on the "editing" of the mental accounting system and allow to draw sharper predictions about how people classify and encode expenditures.

Finally, the emergence of reference-dependence and other recurring patterns in apparently different domains (e.g., utility assessment in terms of variations from a reference level, product evaluations based on various procedures of "anchoring" on other products in the reference set, reference-based similarity judgments, categorization based on prototype-instance matching, etc.) is strongly suggestive of an underlying unitariety of most human cognitive processes, whose further exploration promises as a highly fascinating research program, both in its own right, and for its implications in terms of formal modeling. 
VI. Some concluding remarks on the state of the art and a research agenda

Research on consumer behavior is immense and extremely diversified. The main purpose of this survey has been to provide a critical assessment of selected evidence on consumer decision making which should be taken into account in building alternative micro-foundations of consumption behavior, and to describe some of the most fruitful attempts to create alternative frameworks starting from such evidence.

Several themes have been left out of the survey for reasons of space, but are nonetheless crucial for a behavioral theory of consumption. Learning, in particular, is a key aspect that virtually involves all phases of decision making: various experiments have been conducted which test the role of knowledge and expertise (acquired through learning and familiarity with the product class) in the overall quality of decision making. The effects of learning and expertise are nonetheless somehow ambiguous and still have to be clarified. If choices change with learning, is it because individuals learn to apply more efficient decision rules, or because they develop more stable - and therefore less context-dependent - preferences over time? Or do they learn to refine their mental representations in a way more capable of reflecting the complexity of the environment? Probably all of the above apply, and more research is needed in order to disentangle the single effects (see, e.g., Dosi et al., (1996), for a review of learning theories).

Let us conclude with a few remarks on what we believe might be promising future developments of economic models of consumption towards a more sound psychological foundation, in the light of what has already been done (indeed a lot, but not enough) on such grounds.

The scarce empirical content of many (if not all) assumptions underlying microeconomic theories of consumer choice is being recognized as a well-established fact by an increasing number of theorists, hence the point does not need to be overemphasized here. However, once such theoretical shortcomings are acknowledged, the question of what to do about it still remains a crucial one, to which answers essentially differ on how much should be retained of standard theories and how much should be discarded. At one extreme, the more conservative approaches basically aim at preserving the standard decision-theoretic framework by introducing modifications in the argument of the utility function or by relaxing some of the less normatively compelling axioms. However, it is not clear to what extent such hybrids are able to assure an effective gain in descriptive validity, and where should the limit be placed to the modification of the current axiomatic construction. 
Other approaches explicitly take the other way around and, starting from the empirical evidence, extract some general behavioral principles which are then translated into (quasi-axiomatic) microfoundations of alternative theories. The most successful and influential result of such approaches is indeed Prospect Theory and its adaptations to consumer decision making. To the same line of research belong the various attempts to model intertemporal choice (see Loewenstein and Elster, (1992)). The paradigm of utility-based modeling is retained, although utility itself is redefined, refining on the basis of Bentham's original hedonic interpretation (see Kahneman et al., (1997)).

Notwithstanding the relevance of these theoretical contributions in the development of behavioral models in economic theorizing, there are still several aspects which are left out of these frameworks (some of which have been discussed here), and which, we believe, should be taken on board by behavioral consumpthion models in one way or the other.

More effort should be put in trying to incorporate the contingent nature of most decision processes and by rendering their mechanisms more explicit, while the issue is still often avoided by postulating the maximization of some "behaviorally-adjusted" utility function. In this respect, Shafir et al. (1990a) and Tversky and Simonson (1993) are fruitful attempts to capture the fundamentally contingent and comparative nature of most decision strategies.

Likewise, probabilistic models like Elimination-by-Aspects or Pretree (cf. section iii) are refined mathematical tools to formalize processes of hierarchical selection. The Contrast Model of Similarity (Tversky, (1977); Tversky and Gati, (1978)) is a sharp and parsimonious model of perceived similarity, which is often the basis for cognitive processes that involve recognition and classification of stimuli.

Indeed, a major message of the foregoing discussion concerns the interpretative advancements already achieved by empirically-disciplined "reduced form" representations of choice processes, which exhibit varying degrees of departure from the standard model, while still maintaining a somewhat similar conception of the decision maker as (imperfect) utility maximizer. However, in this work we have also argued that it might be necessary to move a further step ahead.

As Eldar Shafir points out:

\footnotetext{
"As a consequence of the tension between normative predictions and empirical evidence, several alternative theories have been developed that try to effect a synergy between the normative and the descriptive; these theories retain some of the more normatively appealing principles, like dominance and invariance, while relaxing others, like independence and transitivity. It is not clear, however, who these theories are about. They are not about superrational agents, because they
} 
behave in conformity with all the principles and have no good reason to give up any. .....At the same time, these revised theories are not about real people because we, it appears, systematically violate all the principles, including some of the normatively indispensable ones..." (Shafir, (1993), p. 277, italics added).

One way of facing the challenge of a full-fledged descriptive theory is precisely to explicitly account for the cognitive (and eventually also the emotional) structures and processes underlying behaviors and choices. In turn, that involves modeling mental representations, whether seen in terms of mental models, categories, or clusters of rules. We believe that the phenomena related to the formation and evolution of (possibly, socially shared) mental representations is one of the greatest challenges for economics. Accepting the challenge, however, implies an even more radical abandonment of several reassuring conceptions of the economic agents which still abound among economists.

Individuals do not live in a "small world" with a finite set of completely specified options, known a priori in all their relevant characteristics and consequences. Rather, they face an open environment which is far more complex and diversified than their bounded rationality is able to grasp. They face continuos flows of novelty and rely on partial isomorphisms to generate default expectations and rules and behavior. At the same time, individuals are not simply passive recipients of environmental stimuli, or (imperfect) information processing machines. Rather, they actively interpret their own experience and confer meaning to the reality in which they live. Rather than maximizing exogenous and well-behaved preferences and utilities defined over commodity bundles, individuals exhibit (or better, construct) attitudes towards events and objects in so far as these are cognitively perceived as belonging to some more abstract concepts, categories or ideas (see Kahneman et al., (1998)). Moreover, concepts and categories evolve over time as a result of learning, appearence of novelties, acquiring of new information and social communication.

Therefore, preferences as the term is used in economics may be the result of quite inductive and context-dependent processes in which goal-driven mental models, prototype-based expectations interact with intuitive (nonanalytical) heuristics and various processes of (ex-post?) rationalization. Almost every cognitive act is nested into some type of representation. As Holland (1986) puts it,

"people and machines must represent variability in some way, and any future theories of induction must come to grips with the question of variability representation and processing" (Holland et al., 1986, p.). 
We believe that consumption models should try to be more explicitly grounded into general theories of induction. We have no ready answer for how this should be achieved. Our sole aim is to raise the issue and to provide some suggestions on possible fruitful directions.

Some help may come from those theories which have been repeatedly tested empirically and which provide a coherent set of general principles likely to hold across different cognitive domains. Johnson-Laird's mental model theory is one of these. In addition, the probabilistic models of categorization (whether based on feature co-occurrences or default expectations) also possess a reasonable degree of generality and some of their theoretical constructs might be included in models which try to explicit consumers' knowledge in terms of clustered regularities.

In this respect, the model of default hierarchies proposed by Holland et al. may be considered as a part of a more general theory of induction which embraces aspects as diverse as probabilistic inference, learning, analogy, problem solving and stereotyping, within a general rule-based framework that combines results in disciplines ranging from psychology to biology to artificial intelligence. Its substantial degree of generality and flexibility renders it also well suited to model knowledge representation in more specific and economically-relevant domains.

Furthermore, as briefly discussed above, the "biases" identified experimentally may be interpreted as the very properties of the underlying categorization processes. More systematic efforts in this direction are indeed one of the grounds over which the "mental model" view can prove to yield a rather general characterization of economic agency, alternative to the utility maximizing one and rich of empirically testable implications.

In addition, both preferences and mental representations are socially nested, and this is true in particular for consumption behavior. So, for example, categories and prototypes may be seen as "focal" cognitive constructs which allow models of the world to be socially communicated and shared. Attitudes and preferences may be the result of both imitation and affective responses to such common "norms". Therefore, even though the issue has not been addressed here, we are fully aware that a truly behavioral theory of consumption should not neglect the social dimension of consumption acts.

To conclude, we obviously agree with Rabin (1998) in that not all aspects of human nature are relevant to economics, nor they should be. The key scientific issue is deciding what is relevant and what is not. In particular, if one chooses to abandon the traditional, "deductive" approach to modeling behavior (which, it appears, leads us to be "precisely wrong"), and chooses instead to go 
out in the field and (much less precisely) infer empirical regularities from what one observes, then the Pandora box is open.

However, a truly psychological foundation of consumption theory, we have argued, should be a goal worth pursuing by economists, even if this may imply leaving aside the handy, neoclassical toolkit to which many of us are used. One useful starting point may be to take psychology more seriously in what has to offer in terms of "positive", alternative accounts of human behavior, rather than only in terms of the critiques it moves to rational models. As Kahneman et al. (1998) put it:

"The alternative to rational choice as a descriptive model is neither chaos nor an endless list of ad hoc claims. It is a manageable set of concepts and testable propositions, which often predict surprising parallels between ostensibly different behaviors in different domains". Kahneman et al. ((1998), p. 32).

Within this broad program, the search for the cognitive roots of consumption acts, and of their socially shaped evolution, promises to yield novel foundations to consumption theory, much more in tune with experimental evidence, and, hopefully, parsimonious enough to be of use even to economists. 
VII. Appendix: a brief guide to references

The following is a concise list of the topics discussed in the text plus some additional ones with the related references. It is by no means intended as a complete bibliography on the issues cited, but only as a selected guide out of a much wider literature. Several of the books and articles cited may present overlappings with other topics, some of which have not been mentioned in the survey. The order roughly corresponds to the order in which topics have been discussed in the text.

Attraction effect: Aaker, (1991), Burton and Zinkhan, (1987), Heath and Chatterjee, (1991), Heath and Chatterjee, (1995), Huber et al., (1982), Huber and Puto, (1983), Kardes et al., (1989), Mishra et al., (1993), Ratneshwar et al., (1987), Simonson, (1989), Stewart, (1989).

Direction of comparison effect: Dhar and Simonson, (1992), Houston et al., (1989), Johar and Creyer, (1993).

Tradeoff Contrast: Simonson and Tversky, (1992).

Extremeness Aversion (Compromise Effect): Simonson, (1989), Simonson and Tversky, (1992), Wernerfelt, (1995).

Advantage model: Shafir et al., (1989), Shafir et al., (1990), Tversky and Simonson, (1993).

Framing: Kahneman et al., (1982), Levin and Gaeth, (1988), Tversky and Kahneman, (1981), Tversky and Kahneman, (1986).

Preference reversals: Slovic and Lichtenstein, (1968), Tversky and Thaler, (1990).

Intransitivity of preferences: Tversky, (1969).

Heuristics: Bettman et al., (1991), Bettman et al., (forthcoming), Payne, (1976), Payne, (1990),

The Elimination-By-Aspects model: Tversky, (1972). 
Preference Tree and Hierarchical Elimination model: Tversky and Sattath, (1979)

Agendas and constrained choice: Hauser, (1986), Kahn et al., (1987), Tversky and Sattath, (1979).

Similarity: Tversky, (1977), Tversky and Gati, (1978), Johnson, (1986). Johnson et al., (1992).

Prospect Theory and loss aversion: Kahneman and Tversky, (1979), Kahneman, Knetsch and Thaler, (1991), Tversky and Kahneman, (1991).

Endowment effect: Kahneman, Knetsch and Thaler, (1991)

Status quo bias: Kahneman, Knetsch and Thaler, (1991).

Opportunity cost neglect and sunk cost fallacy: Thaler, (1980), Thaler, (1985).

Mental accounting: Thaler, (1985), Thaler, (1998).

Pre-commitment and self-control: O’Donoghue and Rabin, (forthcoming), Loewenstein and Elster, (1992), Thaler, (1994).

Choice over time; Thaler, (1994), Loewenstein and Elster, (1992), and references therein

Reason-based choice and context effects: Shafir et al., (1993), Simonson, (1989).

Reasons and conflict: Tversky and Shafir, (1992a)

Choice under disjunction: Tversky and Shafir, (1992b).

Social accountability: Tetlock, (1992). 
Constructive choice processes: Bettman, (1979), Bettman et al., (1991), Bettman et al., (forthcoming), Payne et al., (1992).

Focussing in decision making: Legrenzi et al., (1993).

Mental model theory of reasoning: Johnson-Laird, (1983), Johnson-Laird and Byrne, (1991).

Schemas: Fiske and Linville, (1980), Fiske and Taylor, (1984), Meyers-Levy and Tybout, (1989), Peracchio and Tybout, (1996), Stayman et al., (1992), Sujan and Bettman, (1989), Taylor and Crocker, (1981).

Scripts: Anderson, (1982), Schank, R. and R.P. Abelson, (1977).

The prototypical model of categorization: Lakoff, (1987), Rosch, (1975a), Rosch, (1975b), Rosch, (1978).

Family resemblance: Rosch and Mervis, (1975), Tversky, (1977), Wittgenstein, (1953).

Levels of categorization: Rosch et al., (1976).

Typicality and consumer choice: Loken and Ward, (1990), Nedungadi and Hutchinson, (1985), Ratneshwar and Shocker, (1988), Saunders et al., (1991), Ward and Loken, (1988).

Category-based versus piecemeal processing of information: Fiske, (1982), Fiske and Pavelchack, (1986), Sujan, (1985).

Choice between noncomparable options: Johnson, (1984), Johnson, (1989), Johnson and Fornell, (1987), Johnson et al., (1992).

The representativeness heuristic in probability judgments: Kahneman and Tversky, (1972), Kahneman et al., (1982), Tversky and Kahneman, (1983). 
Category-based reasoning: Osherson et al., (1990), Rips, (1975), Shafir et al., (1990).

Typicality and attitude formation: Kahneman et al., (1998).

The pioneering Advantage: Carpenter and Nakamoto, (1988), Carpenter and Nakamoto, (1989), Kardes et al., (1992), Kardes et al., (1993).

Goal-derived categories: Barsalou, (1983), Barsalou, (1985)

Alternative views on categorization: Cohen and Basu, (1987), Thompson, (1989).

Rule-based categories: Holland et al., (1986).

Categorization and problem solving: Howard, (1989). 
References

Aaker, J., (1991), The Negative Attraction Effect? A Study of the Attraction Effect Under Judgment and Choice', Advances in Consumer Research, 18, 462-469.

Alba, J.W. and H. Marmorstein, (1987), The Effects of Frequency Knowledge on Consumer Decision Making, Journal of Consumer Research, 14 (June), 14-25.

Anderson, J.R., (1982), 'Acquisition of cognitive skills', Psychological Review, 89, 369-406.

Aversi, R., G. Dosi, G. Fagiolo, M. Meacci, C. Olivetti, (1999), Demand Dynamics With Socially Evolving Preferences', Industrial and Corporate Change, 2,

Baron, J., (1988), Thinking and Deciding, Second Edition, Cambridge: Cambridge University Press.

Barsalou, L.W., (1982), 'Context-independent and Context-dependent Information in Concepts', Memory\&Cognition, 10 (January), 82-93.

Barsalou, L.W., (1983), 'Ad hoc categories', Memory\&Cognition, 11 (May), 211-227.

Barsalou, L. W., (1985), 'Ideals, central tendency, and frequency of instantiation as determinants of graded structure', Journal of Experimental Psychology: Learning, Memory and Cognition, 11 (October), 629-654.

Bettman, (1979), An information processing theory of consumer choice, Reading, MA: Addison-Wesley.

Bettman, J. R., E. J. Jonhson and J. W. Payne, (1991), 'Consumer Decision Making', in Handbook of Consumer Behavior, T. S. Roberston and T. S. Kassarjian, editors. Prentice-Hall.

Bettman, J.R., M.F. Luce, and J.W. Payne, (forthcoming), 'Constructive Consumer Choice Processes', Journal of Consumer Research.

Bettman, J.R. and M. Sujan, (1987), 'Effects of Framing on Evaluation of Comparable and Noncomparable Alternatives by Expert and Novice Consumers', Journal of Consumer Research, 14 (September), 141-154. 
Block, L.G. and P.A. Keller, (1995), 'When to Accentuate the Negative: The Effects of Perceived Efficay and Message Framing on Intentions to Perform a Health-Related Behavior', Journal of Marketing Research, 32 (May), $192-203$.

Blunch, N.J., (1984), 'Position Bias in Multiple-Choice Questions', Journal of Marketing Research, 21 (May), $216-220$.

Bonini, N. and R. Rumiati, (1996), 'Mental Accounting and Acceptance of a Price Discount', Acta Psychologica, 93, 149-160.

Browning, M. and A. Lusardi (1996), 'Household Savings: Micro Theories and Micro Facts', Journal of Economic Literature, 34, 1797-1855.

Burton, S. and G.M. Zinkhan, (1987), 'Changes in Consumer Choice: Further Investigation of Similarity and Attraction Effects', Psychology and Marketing, Vol. 4(3), 255-266.

Camerer, C., (1995), Individual Decision Making', in Handbook of Experimental Economics, Kagel, J.H. and Roth, A.E., editors, Princeton University Press, Princeton.

Carpenter, G.S. and K. Nakamoto, (1988), 'Market Pioneering, Learning and Preference', Advances in Consumer Research, 15, 275-278.

Carpenter, G.S. and K. Nakamoto, (1989), 'Consumer Preference Formation and Pioneering Advantage', Journal of Marketing Research, 26, (August), 285-98.

Cohen, J. B. and K. Basu, (1987), 'Alternative Models of Categorization: Toward a Contingent Processing Framework', Journal of Consumer Research, 13 (March), 455-472.

Corfman, K.P., (1991), 'Comparability and Comparison Levels Used in Choices Among Consumer Products', Journal of Marketing Research, 28 (August), 368-374.

Coupey, E. and K. Nakamoto, (1988), 'Learning Context and The Development of Product Category Perceptions', Advances in Consumer Research, 15, 77-82.

Cripps, J.D. and R.J. Meyer, (1994), 'Heuristics and Biases in Timing the Replacement of Durable Products', Journal of Consumer Research, 21 (September), 304-318.

Devetag, M.G., P. Legrenzi and M. Warglien, (1996), The relevance of irrelevant alternatives', Working Paper N. 2/96, University of Venice, Department of Business Economics and Management'. 
Dhar, R. and S.J. Sherman, (1996), The Effect of Common and Unique Features in Consumer Choice', Journal of Consumer Research, 23, 3 (December), 193-203.

Dhar, R. and I. Simonson, (1992), The Effect of the Focus of Comparison on Consumer Preferences', Journal of Marketing Research, 29, 430-440.

Diamond, W.D. and L. Campbell, (1989), The Framing of Sales Promotions: Effects on Reference Price Change', Advances in Consumer Research, 16, 241-247.

Dosi, G., L. Marengo, and G. Fagiolo, (1996), Learning in evolutionary environments', IIASA, Working Paper, Laxenburg, Austria, forthcoming in K.Dopfer (ed), Advances in Evolutionary Economics, Cambridge: Cambridge University Press.

Engel, J.F., r.D. Blackwell and P.W. Miniard, (1986), Consumer Behavior, New York, The Dryden Press.

Elster, J., (1998), 'Emotions and Economic Theory', Journal of Economic Literature, 36, 47-74.

Fiske, S.T. and P.W. Linville, (1980), 'What does the schema concept buy us?', Personality and Social Psychology Bulletin, 6, 543-557.

Fiske, S.T., (1982), 'Schema-Triggered Affect: Applications to Social Perception', in Affect and Cognition: The 17th Annual Carnegie Symposium on Cognition, M.S. Clark and S. T. Fiske, Hillsdale, NJ: Lawrence Erlbaum, 55-78.

Fiske, S.T. and S.E. Taylor, (1984), Social cognition, Reading, MA: Addison-Wesley.

Fiske, S.T. and M.A. Pavelchak, (1986), 'Category-Based Versus Piecemeal-Based Affective Responses: Developments in Schema-Triggered Affect', in R.M. Sorrentino, and H.T. Higgins, (eds), The Handbook of Motivation and Cognition: Foundations of Social Behavior, New York: Guilford, 167-203.

Friedman, M., (1953), Essays in Positive Economics, Chicago: University of Chicago Press.

Gardner, H., (1985), The mind's new science: A history of the cognitive revolution, New York: Basic Books.

Grewal, D., J. Gotlieb and H. Marmorstein, (1994), The Moderating Effects of Message Framing and Source Credibility on the Price-perceived Risk Relationship', Journal of Consumer Research, 21 (June), 145-153.

Hauser, J.R., (1986), 'Agendas and Consumer Choice', Journal of Marketing Research, 23 (August), 199-212. 
Heath, T.B. and S. Chatterjee, (1991), 'How Entrants Affect Multiple Brands: A Dual Attraction Mechanism', Advances in Consumer Research, 18, 768-772.

Heath, T.B. and S. Chatterjee, (1995), 'Asymmetric Decoy Effects on Lower-Quality versus Higher-Quality Brands: Meta-analytic and Experimental Evidence', Journal of Consumer Research, 22 (December), 268-284.

Heath, T.B., S. Chatterjee and K.R. France, (1995), 'Mental Accounting and Changes in Price: The Frame Dependence of Reference Dependence', Journal of Consumer Research, 22 (June), 90-97.

Heath, C. and J.B. Sall, (1996), 'Mental Budgeting and Consumer Decisions', Journal of Consumer Research, 23, 1 (June), 40-52.

Herr, P.M. and F.R. Kardes, (1989), 'Context Effects in Consumer Judgment and Choice', Advances in Consumer Research, 16, 195-196.

Higgins, E.T. and L. Lurie, (1983), 'Context, Categorization, and Recall: The "Change-of-Standard" Effect', Cognitive Psychology, 15, 525-547.

Hogarth, R. M., (1987), Judgment and choice: The psychology of decision. (Second Edition). New York: Wiley\&Sons.

Holyoak, K.J. and B.A. Spellman, (1993), Thinking', Annual Review of Psychology, 44, 265-315.

Holland, J. H., K. J. Holyoak, R.E. Nisbett and P.R. Thagard, (1986), Induction: Processes of Inference, Learning, and Discovery. The MIT Press, Cambridge, Massachusetts.

Houston, D.A., S. Sherman and S.M. Baker, (1989), The Influence of Unique Features and Direction of Comparison on Preferences', Journal of Experimental Social Psychology, 25(3), 121-141.

Howard, John A., (1989), Consumer Behavior in Marketing Strategy. Prentice-Hall, Inc. Englewood Cliffs, NJ 07632.

Hoyer, W.D., (1984), 'An Examination of Consumer Decision Making for Common, Repeat Purchase Product', Journal of Consumer Research, 11 (December), 822-829.

Huber, J., J.W. Payne and C. Puto, (1982), 'Adding Asymmetrically Dominated Alternatives: Violations of Regularity and the Similarity Hypothesis', Journal of Consumer Research, 9, (June), 90-98.

Huber, J. and C. Puto, (1983), 'Market Boundaries and Product Choice: Illustrating Attraction and Substitution Effects', Journal of Consumer Research, 10 (June), 31-43. 
Jacobson, R. and C. Obermiller, (1989), The Formation of Reference Prices', Advances in Consumer Research, 16, 234-240.

Jacoby, J., G.V. Johar, and M. Morrin, (1998), 'Consumer Behavior: A Quadriennium', Annual Review of Psychology, 49, 319-344.

Johar, G.V. and E.H. Creyer, (1993), The impact of Direction of Comparison on the Formation of Preference', Advances in Consumer Research, 20, 284-287.

Johnson, M.D., (1984), 'Consumer Choice Strategies for Comparing Noncomparable Alternatives', Journal of Consumer Research, 11 (December), 741-753.

Johnson, M.D., (1986), 'Consumer Similarity Judgments: A Test of The Contrast Model', Psychology\&Marketing, 3, 47-60.

Johnson, M.D., (1989), The Differential Processing of Product Category and Noncomparable Choice Alternatives', Journal of Consumer Research, 16 (December), 300-309.

Johnson, M.D and C. Fornell, (1987), The Nature and Methodological Implications of the Cognitive Representations of Products', Journal of Consumer Research, 14 (September), 214-228.

Johnson, M.D., D. Lehmann, D.R., C. Fornell and D.R. Horne, (1992), 'Attribute Abstraction, Feature-dimensionality, and The Scaling of Product Similarities', International Journal of Research in Marketing, 9, 131-147.

Johnson-Laird, PN., (1983), Mental Models: Towards a cognitive science of language, inference and consciousness, Cambridge: Cambridge University Press.

Johnson-Laird, P.N. and R.M.J. Byrne, (1991), Deduction, Lawrence Erlbaum Associates, Publishers, Hove and London (UK), Hillsdale (USA).

Johnson-Laird, P.N., and E. Shafir, (1993), 'The interaction between reasoning and decision making: an introduction', Cognition, 49, 1-9.

Kahn, B., W.L. Moore and R. Glazer, (1987), 'Experiments in Constrained Choice', Journal of Consumer Research, 14, 96-113. 
Kahneman, D., J. Knetsch, and R. Thaler, (1990), Experimental Tests of the Endowment Effect and the Coase Theorem', Journal of Political Economy, XCVIII, 1325-48.

Kahneman, D., J. Knetsch and R. Thaler, (1991), 'Anomalies: The endowment effect, loss aversion and the status quo bias', Journal of Economic Perspectives, 5, 193-206.

Kahneman, D., I. Ritov and D. Schkade, (1998), 'Economists have preferences, psychologists have attitudes: An analysis of dollar responses to public issues', mimeo, Princeton University.

Kahneman, D., P. Slovic and A. Tversky, editors, (1982), Judgment under uncertainty: Heuristics and biases. Cambridge: Cambridge University Press.

Kahneman, D. and A. Tversky, (1972), 'Subjective probability: A judgment of representativeness', Cognitive Psychology, 3, 430-454.

Kahneman, D. and A. Tversky, (1979), 'Prospect theory: An analysis of decision under risk', Econometrica, 47, 26391.

Kahneman, D. and A. Tversky, (1982), 'On the study of statistical intuitions', Cognition, 11, 123-141.

Kahneman, D. and A. Tversky, (1984), 'Choices, Values, and Frames', American Psychologist, vol. 39, No. 4 (April), 341-350.

Kahneman, D. and A. Tversky, (1996), 'On the Reality of Cognitive Illusions', Psychological Review, $103,3,582-591$.

Kahneman, D., P.P. Wakker and R. Sarin, (1997), 'Back to Bentham? Explorations of experienced utility', Quarterly Journal of Economics, 374-405.

Kardes, F.R., P.M. Herr, D. Marlino, (1989), 'Some New Light on Substitution and Attraction Effects', Advances in Consumer Research, 16, 203-208.

Kardes, F.R. and G. Kalyanaram, (1992), 'Order-of-Entry Effects on Consumer Judgment: An Information Integration Perspective', Journal of Marketing Research, 29, 343-357.

Kardes, F.R., G. Kalyanaram, M. Chandrashekaran and R.J. Dornoff, (1993), 'Brand Retrieval, Consideration Set Composition, Consumer Choice and The Pioneering Advantage', Journal of Consumer Research, (June), 20, 62-75. 
Kardes, F.R., D.M. Sanbonmatsu and P.M. Herr, (1990), 'Consumer Expertise and The Feature-Positive Effect: Implications for Judgment and Inference', Advances in Consumer Research, 17, 351-354.

Klein, N.M. and S.W. Bither, (1987), 'An investigation of Utility-Directed Cutoff Selection', Journal of Consumer Research, 14 (September), 240-256.

Klein, N.M. and M.S. Yadav, (1989), 'Context Effects on Effort and Accuracy in Choice: An Enquiry into Adaptive Decision Making', Journal of Consumer Research, 15 (March), 411-421.

Kreps, D., (1990), Game theory and economic modelling, Oxford University Press.

Lakoff, G., (1987), Women, Fire, and Dangerous Things. What categories reveal about the mind, Chicago: The University of Chicago Press.

Lancaster, K.J., (1971), 'Consumer Demand. A New Approach, New York, Columbia University Press.

Legrenzi, P., V. Girotto, and P.N. Johnson-Laird, (1993), 'Focussing in Reasoning and Decision Making', Cognition, 49, $37-66$.

Lehmann, D.R. and Y.Pan, (1994), 'New Brand Entry and Consideration Sets', Journal of Marketing Research, 31 (August), 364-374.

Levine, M.E. and Plott, C.R., (1977), 'Agenda influence and its implications', Virginia Law Review, 63, 561-604.

Levin, I.P. and G.J. Gaeth, (1988), 'How Consumers are Affected by the Framing of Attribute Information Before and After Consuming the Product', Journal of Consumer Research, 15 (December), 374-378.

Lewin, S.B., (1996), 'Economics and Psychology: Lessons For Our Own Day From the Early Twentieth Century', Journal of Economic Literature, 34, 1293-1323.

Loken, B. and J. Ward, (1990), 'Alternative Approaches to Understanding the Determinants of Typicality', Journal of Consumer Research, 17 (September), 111-126.

Loewenstein, G. and J. Elster, editors, (1992), Choice Over Time. Russel Sage Foundation, New York.

Loewenstein, G., and R.H. Thaler, (1989), 'Anomalies: Intertemporal Choice', Journal of Economic Perspectives, vol. 3, N. 4 (Fall), 181-193. 
Luce, R.D., (1977), Individual choice behavior: A theoretical analysis, New York: Wiley.

MacInnis, D., K. Nakamoto and G. Mani, (1992), 'Cognitive Associations and Product Category Comparisons: The Role of Knowledge Structure and Context', Advances in Consumer Research, 19, 260-267.

Manrai, A.K. and P. Sinha, (1989), 'Elimination by Cutoffs', Marketing Science, 8, No. 2, 133-147.

March, J.G., (1994), A Primer on Decision Making, New York, Free Press.

Marengo, L. and H. Tordjman, (1996), 'Speculation, heterogeneity and learning: a model of exchange rate dynamics', Kyklos, 47, 407-438.

Marschak, J., (1960), 'Binary-choice constraints and random utility indicators', In K.J. Arrow, S. Karlin, and P. Suppes (Eds.), Mathematical methods in the social sciences, Stanford, California: Stanford University Press.

Medin, D.L., R.L. Goldstone, and D. Gentner, (1993), 'Respects for Similarity', Psychological Review, Vol. 100, N. 2, 254-278.

Mellers, B.A., A. Schwartz, and A.D.J. Cooke, (1998), 'Judgment and decision making', Annual Review of Psychology, 49, 447-477.

Mervis, C.B. and J.R. Pani, (1980), 'Acquisition of basic object categories', Cognitive Psychology, 12, 496-522.

Mervis, C.R. and E. Rosch, (1981), 'Categorization of natural objects', In M.R. Rosenzweig\&L.W. Porter (Eds.), Annual Review of Psychology, 32, 89-115. Palo Alto, CA: Annual Reviews.

Meyers-Levi, J. And A.M. Tybout, (1989), 'Schema Congruity as a Basis for Product Evaluation', Journal of Consumer Research, 16 (June), p. 39-54.

Mishra, S., U.N. Umesh, D.E. Stem, (1993), 'Antecedents of the Attraction Effect: An Information Processing Theory', Journal of Marketing Research, 30 (August), 331-349.

Nakamoto, K., (1987), 'Alternatives to information processing in consumer research: New perspectives on old controversies', International Journal of Research in Marketing, 4, 11-27.

Nedungadi, P. and J. Hutchinson, (1985), 'The Prototypicality of Brands: Relationships with Brand Awareness, Preference, and Usage', Advances in Consumer Research, 12, 498-503. 
Newell, A., and H.E. Simon, (1972), Human Problem Solving, Englewood Cliffs, NJ: Prentice-Hall.

O’ Donoghue, T., and M. Rabin, (forthcoming), Doing it Now or Later', American Economic Review.

Ofir, C. and J.G. Lynch, JR., (1984), 'Context Effects on Judgment Under Uncertainty', Journal of Consumer Research, 11 (September), 668-679.

Osherson, D.N., E.E. Smith, O. Wilkie, A. Lopez, and E. Shafir, (1990), 'Category based induction', Psychological Review, 97, 185-200.

Ozanne, J.L., M. Brucks and D. Grewal, (1992), 'A Study of Information Search Behavior During the Categorization of New Products', Journal of Consumer Research, 18, 452-463.

Painton, S. And J.W. Gentry, (1985), 'Another Look at the Impact of Information Presentation Format', Journal of Consumer Research, 12 (September), 240-244.

Pan, Y. and D.R. Lehmann, (1993), The Influence of New Brand Entry on Subjective Brand Judgments', Journal of Consumer Research, 20 (June), 76.

Park, C.W. and V.P. Lessig, (1981), The Construct of Familiarity and Its Impact on Consumer Decision Process: Cognitive Biases and Heuristics', Journal of Consumer Research, 8 (September), 223-230.

Park, C.W. and D.C. Smith, (1989), Product-Level Choice: A Top-Down or Bottom-Up Process?', Journal of Consumer Research, 16 (December), 289-299.

Payne, J.W., (1976), Task complexity and contingent processing in decision making: An information search and protocol analysis', Organizational Behavior and Human Performance, 16, 366-387.

Payne, J.W., (1990), The Adaptive Decision Maker: Effort and Accuracy in Choice', in Insights in Decision Making, R. Hogarth editor, Chicago: University of Chicago Press, 129-153.

Payne, J.W., J. Bettman, and E. Johnson, (1992), 'Behavioral decision research: A constructive processing perspective', Annual Review of Psychology, 43, 87-131.

Peracchio, L.A. and A.M. Tybout, (1996), The Moderating Role of Prior Knowledge in Schema-Based Product Evaluation', Journal of Consumer Research, 23, 3 (December), 177-192. 
Plott, C.R. and M.E. Levine, (1978), 'A model of agenda influence on committee decision', American Economic Review, $68,146-160$.

Puto, C., (1987), The Framing of Buying Decisions', Journal of Consumer Research, 14 (December), 301-315.

Rabin, M., (1998), 'Psychology and Economics', Journal of Economic Literature, vol. 36, (March), 11-46.

Ratneshwar, S., C. Peckmann and A. D. Shocker, (1996), 'Goal-Derived Categories and the Antecedents of AcrossCategory Consideration', Journal of Consumer Research, 23, 3 (December), 240-250.

Ratneshwar, S., A.D. Shocker, D.W. Stewart, (1987), Toward Understanding the Attraction Effect: The Implications of Product Stimulus Meaningfulness and Familiarity', Journal of Consumer Research, 13 (March), 520-533.

Ratneshwar, S. and A.D. Shocker, (1988), The Application of Prototypes and Categorization Theory in Marketing: Some Problems and Alternative Perspectives', Advances in Consumer Research, 15, 280-285.

Rips, L.J., (1975), 'Inductive judgments about natural categories', Journal of Verbal Learning and Verbal Behavior, 14, 665-681.

Rosch, E., (1975a), 'Cognitive representations of semantic categories', Journal of Experimental Psychology: General, $104,192-233$.

Rosch, E., (1975b), 'Cognitive reference points', Cognitive Psychology, 7, 532-547.

Rosch, E., (1978), 'Principles of categorization', In Rosch, E., Lloyd, B.B., Cognition and Categorization, Erlbaum, Hillsdale.

Rosch, E. and C.B. Mervis, (1975), 'Family Resemblances: Studies in The Internal Structure of Categories', Cognitive Psychology, 7, 573-605.

Rosch, E., C.B. Mervis, W.D. Gray, D.M. Johnson and P.B. Braem, (1976), 'Basic Objects in Natural Categories', Cognitive Psychology, 8 (July), 382-439.

Saunders, D., S. Tax, J. Ward, K. Court and B. Loken, (1991), The Family Resemblance Approach to Understanding Categorization of Products: Measurement Problems, Alternative Solutions, and Their Assessment', Advances in Consumer Research, 18, 84-89.

Savage, L.J., (1954), The Foundations of Statistics, New York, Wiley. 
Schank, R. and R.P. Abelson, (1977), Scripts, plans, goals, and understanding: An inquiry into human knowledge structures, Hillsdale, NJ: Lawrence Erlbaum.

Shafir, E., (1993a), 'Choosing versus rejecting: Why some options are both better and worse than others', Memory\&Cognition, 21 (4), 546-556.

Shafir, E., (1993b), 'Intuitions about rationality and cognition', in K.I. Manktelow, and D.E. Over (eds), Rationality: Psychological and philosophical perspectives, NY: Routledge.

Shafir, E., D.N. Osherson, and E.E. Smith, (1989), 'An Advantage Model of Choice', Journal of Behavioral Decision Making, Vol. 2, 1-23.

Shafir, E., D.N. Osherson, and E.E. Smith, (1990), 'Comparative Choice and the Advantage Model', in Contemporary Issues in Decision Making, K. Borcherding, O.J. Larichev\& D.M. Messick (Editors), Elsevier Science Publishers B.V. (North-Holland).

Shafir, E., I. Simonson and A. Tversky, (1993), 'Reason-based Choice', Cognition, 49, 11-36.

Shafir, E., E.E. Smith, and D.N. Osherson, (1990), Typicality and reasoning fallacies', Memory \& Cognition, 18 (3), 229-239.

Shafir, E. and A. Tversky, (1995), 'Decision making', in Invitation to Cognitive Science: Thinking, D. Osherson and E.E. Smith, editors (Second Edition), MIT Press.

Simon, H.A., (1955), 'A behavioral model of rational choice', Quarterly Journal of Economics, 69, 99-118.

Simon, H.A., (1956), 'Rational choice and the structure of the environment', Psychological Review, 63, 129-138.

Simonson, I., (1989), 'Choice Based on Reasons: The Case of Attraction and Compromise Effects', Journal of Consumer Research, 16, 158-174.

Simonson, I., (1993), 'Get closer to your customers by understanding how they make choices', California Management Review (Summer), 68-84.

Simonson, I. and A. Tversky, (1992), 'Choice in Context: Tradeoff Contrast and Extremeness Aversion', Journal of Marketing Research, 29, 281-295. 
Slovic, P., (1972), 'From Shakespeare to Simon: Speculations - and Some Evidence - About Man's Ability to Process Information', Oregon Research Institute Bulletin, 12, (3).

Slovic, P., and S. Lichtenstein, (1968), 'The relative importance of probabilities and payoffs in risk taking', Journal of Experimental Psychology, 78, 1-18.

Smith, E.E. and D.L. Medin, (1981), Categories and concepts, Cambridge, MA: Harvard University Press.

Smith, E.E., E. Shafir, and D. Osherson, (1993), 'Similarity, plausibility and judgments of probability', Cognition, 49, 67-96.

Staw, B.M., (1997), The escalation of commitment: An update and appraisal', in Organizational Decision Making, Z. Shapira editor, Cambridge: Cambridge University Press, 191-215.

Stayman, D.M., D.L. Alden and K.H. Smith, (1992), 'Some Effects of Schematic Processing on Consumer Expectations and Disconfirmation Judgments', Journal of Consumer Research, 19 (September), 240-255.

Stewart, D., (1989), 'On the Meaningfulness of Sensory Attributes: Further Evidence on the Attraction Effect', Advances in Consumer Research, 16, 197-201.

Sujan, M., (1985), 'Consumer Knowledge: Effects on Evaluation Strategies Mediating Consumer Judgments', Journal of Consumer Research, 12 (June), 31-46.

Sujan, M. And J.R. Bettman, (1989), 'The Effects of Brand Positioning Strategies on Consumers' Brand and Category Perceptions: Some Insights From Schema Research', Journal of Marketing Research, 26, 454-467.

Taylor, S.E., and J. Crocker, (1981), 'Schematic bases of social information processing', in E.T. Higgins, C.P. Herman and M.P. Zanna (eds.), Social cognition: The Ontario Symposium, Vol. 1, Hillsdale, NJ: Lawrence Erlbaum.

Tetlock, P.E., (1992), 'The impact of accountability on judgment and choice: Toward a social contingency model', Advances in Experimental Social Psychology, 25, 331-377.

Thaler, R. H., (1980), Towards a positive theory of consumer choice', Journal of Economic Behavior and Organization, $1,39-60$.

Thaler, R. H., (1985), 'Mental accounting and consumer choice', Marketing Science, 4, 199-214. 
Thaler, R. H. (1987), 'The psychology of choice and the assumptions of economics', in Laboratory experimentation in economics: six points of view, A. Roth, editor, Cambridge: Cambridge University Press.

Thaler, R.H., (1990), 'Saving, Fungibility and Mental Accounts', Journal of Economic Perspectives, 4, 193-205.

Thaler, R.H., (1992), 'The winner's curse: Anomalies and paradoxes of economic life', New York: The Free Press.

Thaler, R.H., (1994), 'Quasi Rational Economics', Russel Sage Foundation, New York.

Thaler, R.H., (forthcoming), 'Mental Accounting Matters', in D. Kahneman and A. Tversky (eds), Choice, Values, and Frames, Cambridge: Cambridge University Press.

Thompson, C.J., (1989), The Role of Context in Consumers' Category Judgments: A Preliminary Investigation', Advances in Consumer Research, 16, 542-547.

Tversky, A., (1969), 'Intransitivity of preferences', Psychological review, 76, 31-48.

Tversky, A., (1972), 'Elimination By aspects: A theory of choice', Psychological Review, 79, 281-99.

Tversky, A., (1977), 'Features of similarity', Psychological Review, 84, 327-352.

Tversky, A. and Gati, (1978), 'Studies of similarity', In Rosch, E., Lloyd, B.B., Cognition and Categorization, Erlbaum, Hillsdale.

Tversky, A. and D. Kahneman, (1981), The framing of decisions and the psychology of choice', Science, 211, 453-458.

Tversky, A. and D. Kahneman, (1983), 'Extensional Versus Intuitive Reasoning: The Conjunction Fallacy in Probability Judgment', Psychological Review, 90, 4, 293-315.

Tversky, A. and D. Kahneman, (1986), 'Rational choice and the framing of decisions', in Journal of Business, 59, S251S278. Reprinted in Rational choice: The contrast between economics and psychology, R. Hogarth and M. Reders, editors, Chicago: University of Chicago Press, 1987.

Tversky, A. And D. Kahneman, (1991), 'Loss aversion in riskless choice: A reference dependent model', Quarterly Journal of Economics, 106, 1039-61.

Tversky, A. and S. Sattath, (1979), 'Preference Trees', Psychological Review, vol. 86, n. 6, 542-573. 
Tversky, A. and E. Shafir, (1992a), 'Choice under conflict: The Dynamics of Deferred Decision', Psychological Science, vol. 3, No. 6 (November), 358-361.

Tversky, A. and E. Shafir, (1992b), The disjunction effect in choice under uncertainty', Psychological Science, 3, 5, 305-309.

Tversky, A. and I. Simonson, (1993), 'Context-dependent preferences: The relative advantage model', Management Science, 39, 1179-89.

Tversky, A. and R.H. Thaler, (1990), 'Preference reversals', Journal of Economic Perspectives, 4, 201-11.

Urbany, J.E., W.O. Bearden and D.C. Weilbaker, (1988), The Effect of Plausible and Exaggerated Reference Prices on Consumer Perceptions and Price Search', Journal of Consumer Research, 15 (June), 95-110.

Wagner, J.A. and N.M. Klein, (1993), 'The Effect of Familiarity on Consumers' Choice Agendas', Advances in Consumer Research, 15, 55-61.

Ward, J. and B. Loken, (1988), The Generality of Typicality effects on Preference and Comparison: An Exploratory Test', Advances in Consumer Research, 15, 55-61.

Warlop, L. and S. Ratneshwar, (1993), The Role of Usage Context in Consumer Choice: A Problem Solving Perspective', Advances in Consumer Research, 20, 377-382.

Wernerfelt, B., (1995), 'A Rational Reconstruction of the Compromise Effect: Using Market Data to Infer Utilities', Journal of Consumer Research, 21, 4 (March), 627-633.

Winer, R.S., (1986), 'A Reference Price Model of Brand Choice for Frequently Purchased Products', Journal of Consumer Research, 13 (September), 250-256.

Wittgenstein, L., (1953), Philosophical investigations, New York: Macmillan.

Wright, P., and F. Barbour, (1975), The relevance of decision process models in structuring persuasive messages', Communications Research, 2, 246-259. 